\title{
A COMPARISON OF CONTEMPORARY PORTABLE X-RAY SYSTEMS
}

\author{
Jessica Ruth Dillon
}

A thesis submitted to the faculty at the University of North Carolina at Chapel Hill in partial fulfillment of the requirements for the degree of Master of Science in the School of Dentistry (Oral and Maxillofacial Radiology).

Chapel Hill

2020

Approved by:

Brandon Johnson

Angela Broome

Marija Ivanovic

John Ludlow 
(C) 2020

Jessica Ruth Dillon

ALL RIGHTS RESERVED 


\section{ABSTRACT \\ Jessica Ruth Dillon: A Comparison of Contemporary Portable X-ray Systems (Under the direction of Brandon Johnson) \\ Using optically stimulated luminescent (OSL) dosimetry, full mouth series (FMX)}

effective dose (E) and operator dose were calculated for adult and child anthropomorphic phantoms using a wall-mounted source with circular collimation (Cir) and rectangular collimation (RC), the NOMAD Pro $2^{\mathrm{TM}}$ handheld with Cir and $\mathrm{RC}$, and the Xray2go handheld with Cir. To assess the impact of RC on exposure, an exploratory device positioning technique was evaluated. Technique errors and line pair resolution (LP) were also assessed. Dosimetry differences were analyzed using Analysis of Variance.

Adult handheld E with Cir was significantly lower than conventional Cir for both handheld devices $(\mathrm{p}<.0001)$. Child handheld E with Cir was similar to conventional Cir for the $\operatorname{NOMAD}^{\mathrm{TM}}(\mathrm{p}=.0984)$. RC E was significantly lower than all Cir $(\mathrm{p}<.0001)$. Operator groin dose was significantly higher than thyroid, chest and trigger hand for all handheld modalities $(\mathrm{p}<.0001)$. Prevalence of technique errors was not different between devices $(p=.07)$. Mean LP resolution was similar for all modalities. 
PREFACE

LCDR Jessica R. Dillon, Dental Corps, Navy Medicine Education, Training and Logistics Command, is a resident at the University of North Carolina at Chapel Hill Adams School of Dentistry, training in Oral and Maxillofacial Radiology.

The views expressed in this article reflect the results of research conducted by the author and do not necessarily reflect the official policy or position of the Department of the Navy, Department of Defense, nor the United States Government.

I am a military service member of the United States government. This work was prepared as part of my official duties. Title 17 U.S.C. 105 provides that 'copyright protection under this title is not available for any work of the United States Government.' Title 17 U.S.C 101 defines a U.S. Government work as work prepared by a military service member or employee of the U.S. Government as part of that person's official duties. 


\section{TABLE OF CONTENTS}

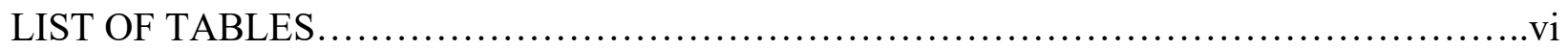

LIST OF FIGURES...........................................................

LIST OF ABBREVIATIONS AND SYMBOLS .....................................viii

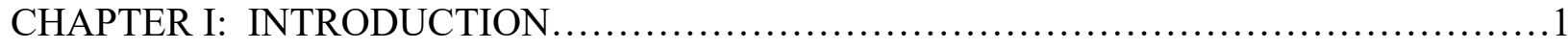

CHAPTER II: REVIEW OF LITERATURE........................................4

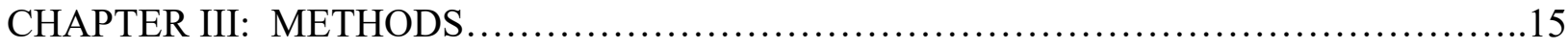

A. Dosimetry Component.................................................. 15

B. Technical Performance and Image Quality Component...........................22

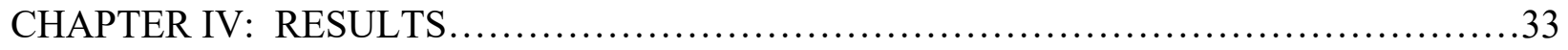

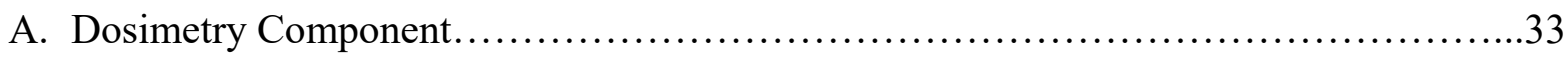

B. Technical Performance and Image Quality Component...........................36

CHAPTER V: DISCUSSION ....................................................... 49

APPENDIX A: ATOMmax Phantom Levels for Dosimeter Locations (Adult and Child).......62

APPENDIX B: CIRS Phantom OSL Dosimeter Locations (Adult and Child)................63

APPENDIX C: Estimated Percent of Tissue Irradiated and OSL

Locations for Adult and Child Phantom............................................65

APPENDIX D: 2007 Tissue Weighting Factors for Calculation

of Effective Dose - ICRP 2007 Recommendations....................................67

APPENDIX E: Criteria Used to Assess the Technical Quality of the Projections..................68






\section{LIST OF TABLES}

\section{TABLE}

3.1 Specifications of X-ray Systems...................................... 31

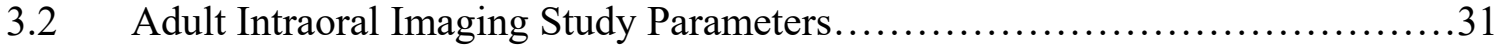

3.3 Child Intraoral Imaging Study Parameters............................... 31

3.4 Dosimetry Acquisition Study Matrix........................................

4.1 Percent Reduction in Adult Effective Dose When Compared to the FOCUS ${ }^{\mathrm{TM}}$ Conventional Source with Circular Collimation.................46

4.2 Percent Reduction in Surface Area Exposure Achieved by All Modalities..........................................................46

4.3 Percent Reduction in Child Effective Dose When Compared to the FOCUS ${ }^{\mathrm{TM}}$ Conventional Source with Circular Collimation

4.4 Frequency and Percentage of All Technique Errors by Modality................47

4.5 Frequency and Percentage of All Technique Errors by Location in the Mouth...48

4.6 Average Number of Line Pairs Observed for Each Modality....................48 


\section{LIST OF FIGURES}

FIGURE

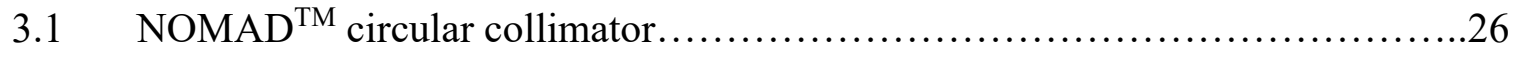

3.2 $\mathrm{NOMAD}^{\mathrm{TM}}$ rectangular collimator.....................................26

3.3 Xray2go circular collimator......................................... 27

$3.4 \quad$ FOCUS $^{\mathrm{TM}}$ Circular collimator..........................................27

3.5 FOCUS ${ }^{\mathrm{TM}}$ Rectangular collimator..................................... 28

3.6 Optimized Exposure Parameters and Corresponding Images...................28

3.7 Average Adult Tissue-Equivalent Phantom (ATOMmax

Model 711HN - Cirs Inc., Norfolk, VA).................................29

3.8 Average Child Tissue-Equivalent Phantom (ATOMmax

Model 706 HN - Cirs Inc., Norfolk,VA)..................................29

3.9 OSL Dosimeters (Nanodot, Landauer, Inc., Glenwood, IL).....................30

3.10 Portable OSL reader (Microstarii, Landauer, Inc., Glenwood, IL)...............30

4.1 Adult Effective Dose $(\mu \mathrm{Sv})$ by Modality.............................. 39

4.2 Adult Normalized Effective Dose (uSv) by Modality .......................40

4.3 Child Effective Dose $(\mu \mathrm{Sv})$ by Modality ............................... 41

4.4 Child Normalized Effective Dose (uSv) by Modality......................42

4.5 Operator Dose ( $\mu \mathrm{Gy})$ To the Four Areas of Interest by

Handheld Modality per Adult FMX Using the Exploratory

Handheld Positioning.

4.6 Comparing Operator Dose ( $\mu$ Gy) To the Four Areas

of Interest by Handheld Modality per Adult FMX From

the Exploratory Handheld Positioning with Manufacturer

Recommended Positioning.

4.7 Operator Dose ( $\mu \mathrm{Gy})$ To the Four Areas of Interest

by Handheld Modality per Child FMX Using the Exploratory

Handheld Positioning. .45 


\section{LIST OF ABBREVIATIONS AND SYMBOLS}

ADA - American Dental Association

ALARA - As Low As Reasonably Achievable

ANOVA - Analysis of Variance

BWX - Bitewing projection

CBCT - Cone Beam Computed Tomography

$\mathrm{CC}$ - Cone Centering

CIRS ATOM Max - Computerized Imaging Reference Systems, Inc. Diagnostic Head Phantom

DXTTR - Dental X-ray Technique Training Replica

E - Effective Dose

FMX - Full Mouth Series

Adult: $(18$ intraoral projections $=14$ periapicals and 4 bitewings $)$

Child: (12: intraoral projections $=10$ periapicals and 2 bitewings $)$

$\mathrm{H}$ - Horizontal Angulation

ICRP - International Commission on Radiation Protection

$\mathrm{kVp}-$ Kilovoltage Potential

LP - Line Pair

mA - MilliAmperage

$\mathrm{mR}$ - Milliroentgen

NCRP - National Commission on Radiation Protection

OSLD - Optically Stimulated Luminescent Dosimeter

$\mathrm{P}$ - Packet (sensor/receptor) placement

PA - Periapical Projection

PID - Position Indication Device 
PSP - Photostimulable Phosphor

RINN - American dental equipment manufacturer

EPR - Electronic Patient Record

V - Vertical Angulation

XCP - Extension Cone Paralleling (Instrument)

$\mu$ - micro

$\mu \mathrm{Gy}$ - micrograys

$\mu \mathrm{Sv}-$ microsieverts 


\section{CHAPTER I}

\section{INTRODUCTION}

Within the last 30 years technological advancements in dental imaging including cone beam computed tomography, digital imaging and handheld x-ray devices have changed the landscape of dentistry and the way we practice for the better. However, these advancements do not come without risks or concern over the diagnostic quality of resultant images and patient and operator safety as there is substantial evidence for a cumulative dose-related response to ionizing radiation in the form of cancer developing years after initial exposure ${ }^{1,2}$. While dose reduction methods and image quality optimization for conventional wall-mounted $\mathrm{x}$-ray sources are wellestablished, relatively less research has been done on handheld x-ray devices.

Current handheld x-ray devices may be used on a tripod or mobile support, but systems such as the NOMAD ${ }^{\mathrm{TM}}$ Pro2 (KaVo Kerr, Brea, $\mathrm{CA}$ ) are designed to be held by the operator in both hands when exposing radiographs. The proximity of the operator to the x-ray source has created increased concern about handheld devices. Approaches used by some manufacturers of handheld devices to overcome safety challenges include the use of internal shielding against leakage radiation and external backscatter shields against scatter radiation created within the patient. Initial studies have shown when properly shielded handheld devices are used according to the manufacturer's instructions (holding the device so that the x-ray beam remains parallel to the floor and perpendicular to the operator), the dose to the patient and operator is comparable or less than that of conventional wall-mounted sources ${ }^{3,4}$. There are multiple instances however, where it is not feasible or expedient to position handheld devices in the recommended position 
such as use during forensic exams or in the operating room. Anecdotally, it is also believed many operators in dental schools and private practice dental offices do not follow strict adherence to the manufacturer's instructions for a variety of reasons. This study investigated dose using handheld devices in various positions/angulations.

Multiple handheld devices are available for purchase on the internet; however, not all are proven safe. Dentists in the United States are responsible for ensuring any handheld device they use has been cleared by the U.S Food and Drug Administration (FDA). Furthermore, the Conference of Radiation Control Program Directors (CRCPD) recommends that each handheld $\mathrm{x}$-ray device be evaluated individually for safety purposes as the design characteristics vary significantly from one manufacturer to another. ${ }^{5}$ This study addressed this recommendation by evaluating an FDA cleared handheld device that is new to the market in the state of North Carolina, the Xray2go (Digital Doc LLC, El Dorado Hills, California).

The use of rectangular collimation is one of the most important methods to minimize radiation dose and optimize image quality with intraoral imaging. It is considered the standard of practice for routine periapical and bitewing intraoral radiography unless patient anatomy or behavior does not allow for its use ${ }^{1}$. Collimating the $\mathrm{x}$-ray beam to the precise size of the image receptor decreases the volume of irradiated tissue in the patient and therefore decreases the amount of scatter radiation created within the patient which contributes to improved image quality. In regard to handheld devices, a decrease in patient dose and scatter radiation will logically also decrease potential dose to the operator. Surprisingly many handheld devices do not allow for a rectangular collimator attachment and there appears to be an emphasis on the use of circular collimation with handheld devices. This study was the first to the author's knowledge 
to evaluate the impact of rectangular collimation with a handheld $\mathrm{x}$-ray device on operator and simulated adult and child patient doses as well as radiographic image quality.

Therefore, the purpose of this study was to measure and compare adult and child effective dose (E) and operator dose from simulated full mouth series (FMX) using an exploratory "real world" positioning technique. Additionally, technical performance and image quality were evaluated from two handheld $\mathrm{x}$-ray devices and one conventional wall-mounted $\mathrm{x}$ ray source using both circular and rectangular collimation. A primary goal was to evaluate the impact of rectangular collimation on operator dose and patient $\mathrm{E}$ as well as image quality. Specific research objectives were:

1. Measure adult and child effective dose from the NOMAD ${ }^{\mathrm{TM}}$ Pro2 handheld device (circular \& rectangular collimation), Xray2go handheld device (circular collimation) and $\mathrm{KaVo}^{\mathrm{TM}}$ FOCUS $^{\mathrm{TM}}$ Instrumentarium conventional wall-mounted source (KaVo Kerr, Brea, CA) (circular and rectangular collimation).

2. Evaluate dose reduction from the $\mathrm{NOMAD}^{\mathrm{TM}} \mathrm{Pro} 2$ with the original equipment manufacturer (OEM) rectangular collimator attachment.

3. Evaluate operator dose from the NOMAD ${ }^{\mathrm{TM}}$ Pro2 handheld device versus the Xray2go handheld device.

4. Evaluate and compare the technical performance and image quality from the NOMAD ${ }^{\mathrm{TM}}$ Pro2 handheld device (circular \& rectangular collimation), Xray2go handheld device (circular collimation) and $\mathrm{KaVo}^{\mathrm{TM}}$ FOCUS ${ }^{\mathrm{TM}}$ Instrumentarium conventional wallmounted source (circular and rectangular collimation). 


\section{CHAPTER II}

\section{REVIEW OF LITERATURE}

The use of handheld x-ray devices in dentistry has increased over the last 25 years and the development of and marketing for these devices is also growing ${ }^{6}$. Early handheld x-ray devices were designed for use by military dental personnel in deployment and field operations $^{7}$. In 1992, the handheld dental x-ray machine (HDX) was developed by the United States Army Research and Development Command and tested in a NATO joint exercise. The device was approved by the U.S Food and Drug Administration (FDA) and was intended to replace the Siemens field dental x-ray unit, which was larger and heavier. The HDX incorporated a 4.5-pound medical collimator for limited medical examinations. The total weight of the HDX, medical collimator and carrying case with battery pack was about 35 pounds $^{7}$. In 2003, Aribex (Aribex Inc., Charlotte, NC) introduced the first light weight handheld x-ray device to incorporate the power source in the same enclosure as the x-ray head and the development of similar devices followed ${ }^{8}$. Many handheld x-ray devices may be used on a tripod or mobile support, but they are specially designed to be held by the operator when exposing radiographs and the latter style of operation is of most interest with respect to radiation safety. Their appearance may resemble either a photographic camera or have a "shotgun" design". Common applications in dentistry include humanitarian work, forensic dentistry and in the surgical setting where patients are sedated ${ }^{10}$. Their portability also makes them advantageous for the growing elderly population with mobility and transportation issues, in temporary and public health clinics and increasingly so for general dental practice. One 
device can be used for multiple operatories, decreasing the cost and maintenance of multiple wall-mounted units, and there are no limitations from a support arm when using a wallmounted source ${ }^{5}$. The use of handheld x-ray devices has also expanded in medicine, veterinary work and security screenings ${ }^{11}$. Even so, their use for the masses is yet to be seen. Early studies regarding basic radiation safety and image quality can be found in the literature but there are still questions about handheld devices prevalent in colloquial conversations in dentistry.

All dentists use and rely on radiographs to some extent. Consequently, it is their responsibility to understand and minimize the risks of ionizing radiation in their practice and be able to accurately and with perspective explain these risks to their staff and patients. The International Commission on Radiological Protection (ICRP) determined the preferred unit for comparing risk from different radiographic examinations is effective dose ${ }^{12}$. This unit is used to estimate the risk to the population of low dose ionizing radiation to the probability of developing stochastic effects e.g., cancer formation. The National Council on Radiation Protection and Measurements (NCRP) Report No. 160 found exposure from medical computed tomography and nuclear medicine examinations contributes $36 \%$ of the estimated average effective dose of 6.2 millisieverts received per person in the United States annually. This report also showed a rapid surge in use of medical imaging since the early $1980 \mathrm{~s}^{13}$. Conversely, radiation exposure from diagnostic dental imaging has been considered a minor contributor of the estimated annual dose received per person. Occupational exposure to workers in the healing arts (such as dental technicians) is also considered a small contributor of exposure to the population of the United States. However, in 2007, the ICRP updated its radiation protection recommendations and increased tissue weighting factors for some tissues 
in the maxillofacial region. Consequently, imaging from dental procedures contributes more to effective dose and the population's radiation burden than previously thought ${ }^{14}$. As the use of CBCT, digital imaging and handheld $\mathrm{x}$-ray devices is growing in dentistry, so must our commitment to maintain patient, occupational and public ionizing radiation exposure as low as reasonably achievable (ALARA) while maintaining high quality, diagnostic images.

Historically, the dental profession has made improvements to best practice techniques and armamentarium including faster receptors, digital imaging and collimation of the x-ray beam in order to minimize radiation doses and limit the release of radiation into the environment. Nolan's 1953 study was one of the first to focus on factors which can protect the patient from overexposure to radiation. He evaluated the effects of $x$-ray energy, focal distance, amount of filtration, x-ray current, time of exposure, type of collimation and type of film and found patient exposure ranged from 35 to $315 \mathrm{R} /$ full mouth examination and averaged 12.6 R/film ${ }^{15}$. A follow up study by Richards showed the effects of the faster Ektaspeed film compared with the very slow regular film of the 1920 ' $\mathrm{s}^{16}$. He reported a reduction in patient exposure to $170 \mathrm{mR} /$ film and $143 \mathrm{mR} /$ film with and without backscatter, respectively.

Richards also evaluated occupational exposure and reported on techniques and equipment available in the 1960 's to reduce dose ${ }^{17}$. One of the simplest techniques to reduce patient dose is rectangular collimation, which is well studied with conventional wall-mounted x-ray sources. The use of rectangular collimation reduces effective dose to the patient up to $80 \%{ }^{14}$. This drastic reduction in patient dose also reduces scatter radiation created within the patient and improves image quality. Optimization of patient dose also reduces potential operator exposure. Although the most recent data show the dose of ionizing radiation received by dental workers has declined to very low levels and supports the profession's adherence to 
the latest guidelines ${ }^{18-20}$, the use of rectangular collimation is still not universally adopted despite consistent strong recommendations by the NCRP. Furthermore, there is even less information regarding the use of rectangular collimation with handheld x-ray devices.

While handheld x-ray devices have obvious similarities to conventional wall-mounted systems, a safe handheld device will also have important differences including its shielding design. NCRP Report No. 177 states traditional methods of shielding and source-to-operator distance are not applicable to handheld devices and that the instruction for the operator to "never hold the x-ray unit" is both unnecessary and impractical for properly designed handheld systems that have been cleared by the FDA ${ }^{1}$. That being said, an improperly designed handheld device may present several safety issues including high radiation doses to patients and operators ${ }^{6}$.

Early studies on the safety and feasibility of handheld devices researched the first handheld device available on the market, the $\mathrm{NOMAD}^{\mathrm{TM}}$. A handheld image quality study in 2008 by Brooks et. al compared diagnostic quality of patient images obtained using a splitmouth design, the NOMAD ${ }^{\mathrm{TM}}$ and a conventional wall-mounted $\mathrm{x}$-ray source. They found image quality was similar and motion artifact was not significant ${ }^{21}$. The same year a clinical study by Goren and colleagues tested the $\mathrm{NOMAD}^{\mathrm{TM}}$ for leakage radiation and patient and operator dose. Using thermoluminescent dosimetry (TLD) and F-speed film at .25 seconds for a lower anterior periapical and a molar bitewing, they found patient exposure ranged $14-27$ $\mathrm{mR} /$ film and the estimated maximum annual operator exposure was $18 \mathrm{mR}$ to the operator's chest, $22.5 \mathrm{mR}$ to the operator's eye, and $45 \mathrm{mR}$ to the operator's finger. With this estimate it was concluded operator doses would be well below $500 \mathrm{mrem} / \mathrm{year}$, the threshold that mandated the use of personal dosimeters in New York State at the time. Scatter measurements 
also fell significantly below the maximum permissible radiation leakage of $100 \mathrm{mR} /$ hour $^{22}$ under 21 CFR $1020.30(\mathrm{k})$. It was concluded that the $\mathrm{NOMAD}^{\mathrm{TM}}$ presented risks that are no greater than conventional wall-mounted systems. Of note, the device was operated with the beam parallel to the floor and the lead filled acrylic shield attached to the end of the x-ray tube. No mention of collimation was made but it can be assumed from photographs in the manuscript that standard ubiquitous circular collimation was implemented.

A follow up study by Hermsen using the NOMAD ${ }^{\mathrm{TM}}$ evaluated operators standing at various positions and angles outside of the recommended "zone of occupancy," in order to resemble working conditions in a morgue setting. Using a Keithley Integrating Radiation Survey Meter and a Lucite cylinder phantom, they concluded the dose received by team members during a typical forensic deployment was at most $.253 \mathrm{mSv}$ and insignificant compared to the $50 \mathrm{mSv}$ annual limit. They also showed that removing the lead infused acrylic ring resulted in radiation readings almost 10 times higher than measurements when the ring was in place $e^{23}$.

In 2009 Danforth et. al studied atypical device positioning using the NOMAD ${ }^{\mathrm{TM}}$ at various angulations with a combination of different film speeds and digital sensors ${ }^{24}$. The highest deep dose to the operator was to the reproductive area and the annual extrapolated whole-body dose from their study was $0.45 \mathrm{mSv}$ or $0.9 \%$ of the annual maximum permissible dose (MPD). Compared to the manufacturer's publications, their calculated whole-body dose was approximately $30 \%$ less, which may be explained by varying methods of measuring dose. Regardless, they concluded even atypical imaging scenarios have no detrimental impact upon the overall operator whole body annual dose. They suggest that the operator using a handheld $\mathrm{x}$-ray device will have to make an individual determination as to how the concept of ALARA 
applies to each diagnostic task at hand.

Following the optimistic findings of early studies using the NOMAD ${ }^{\mathrm{TM}}$ handheld device, the Conference of Radiation Control Program Directors came out with their QA Collectible on handheld dental x-ray units in 2010, cautioning dental providers that not all handheld devices are created equal. They particularly emphasized the use of a backscatter shield, higher tube current to reduce exposure time and potential motion, using high speed receptors and the use of an aiming ring to minimize cone cutting ${ }^{5}$. They also mention optimizing design to reduce patient (and staff) dose by using smaller cylinder diameters, which refers to circular collimation.

In 2010 Pittayapat and colleagues evaluated three portable handheld x-ray units and one wall-mounted system in combination with four types of receptors and were interested in which combination of portable x-ray device and image receptor provided the best images. Secondarily they aimed to evaluate the medical physics parameters and estimate patient and operator exposures. Observers scored images using a 4-point scale (3-excellent, 2-good, 1poor, 0 -very poor) based on image quality properties including image brightness/contrast, visibility of the cemento-enamel junction and the pulpal outline and root apex contour. They found the NOMAD ${ }^{\mathrm{TM}}$ with phosphor image plates yielded the highest image quality score ${ }^{25}$. They also found the Rextar ${ }^{\circledR}$, a newly developed handheld unit with integrated computer, combined with the Sopix ${ }^{\circledR}$ receptor yielded good image quality. The Vatech AnyRay® device had significantly lower image quality likely due to its short $100 \mathrm{~mm}$ cone length. Patient dose estimation done by a medical physicist found the AnyRay ${ }^{\circledR}$ system presented at least a three times higher estimated effective dose as compared to the other devices. The lowest dose estimation was from the MinRay wall-mounted source. They determined large differences in 
effective dose were mostly a consequence of different geometries between the conventional wall-mounted system (300 $\mathrm{mm}$ source to collimator end length and square collimation) and the portable systems ${ }^{25}$. They also showed exposure to the operator's hand was lowest when a protective shield was present. Their results support the use of long cone systems, rectangular collimation and a shield to reduce backscatter, however continued questions about safety are implied when they suggested the use of a tripod and/or an exposure switch cable.

Initial studies showed properly shielded handheld x-ray devices, which includes the use of a backscatter shield, are in accordance with national radioprotection criteria and image quality is comparable to wall-mounted units ${ }^{3,4}$. However, since the use of these devices is highly user dependent, additional research is warranted. Historically there had also been pushback from individual states in the United States and various international dental communities which limited their use and may have generated longstanding suspicion about whether handheld x-ray devices are safe.

It could be argued that operators of conventional wall-mounted x-ray systems should receive zero dose and therefore operators of handheld devices may need additional shielding in order to maintain the principle of ALARA. In 2012 Gray et. al surveyed dental facilities that used conventional wall mounted systems, then implemented the NOMAD ${ }^{\mathrm{TM}}$ handheld system while using radiation monitoring for their staff for both systems. They showed the average monthly dose for NOMAD ${ }^{\mathrm{TM}}$ dosimeters was statistically significantly lower at $0.28 \mu \mathrm{Sv}$ compared to the wall-mounted average dose of $7.86 \mu \mathrm{Sv}$. These results were also in reasonable agreement with data from multiple NCRP reports and a national dosimetry provider showing that the average dose received by dental staff was in fact higher than the NOMAD ${ }^{\mathrm{TM}}$ average in their study. Their conclusion states staff doses for handheld systems are 
significantly less than wall mounted systems and that additional shielding efforts (e.g. wearing a lead apron) are not necessary for handheld devices ${ }^{3}$. It is important to note that the aforementioned study only evaluated dose from the $\mathrm{NOMAD}^{\mathrm{TM}}$ handheld device.

McDiff and colleagues also supported the conclusion that no additional protection requirements are needed for properly trained operators of well-designed handheld x-ray units, which implies operating the handheld device parallel floor ${ }^{4}$. A study by $\mathrm{Cho}^{26}$ on two handheld x-rays devices sold in Korea recommended the use of a backscatter shield, longer cone as well as lead gloves to decrease operator radiation dose. However, the authors state many handheld devices on the market in Korea do not have radioprotective shielding on the collimator cone, which affects operator dose at the level of the hand. Although calculating operator dose was not a major aim in this study, not reporting organ doses limits comparability to other studies on handheld devices.

In 2015 the European Academy of Dentomaxillofacial Radiology determined portable x-ray devices should be used in specific cases only ${ }^{9}$. Recent studies from international dental communities including the United Kingdom, Germany and Canada are addressing the concept of a restricted access "controlled area" (CA) with the use of handheld devices. In 2016 Makdissi et. al studied three test scenario positions of a handheld device relative to the operator (1. Close to the body and x-ray beam parallel to the ground 2. Away from the body and x-ray beam parallel to the ground and 3. Arms partially extended and x-ray beam perpendicular to the ground). In their study the maximum dose to the operator was recorded for the left palm of the support hand when the device was held with the x-ray beam perpendicular to the ground. They concluded device position significantly affects the overall exposure to the operator. Although all doses were negligible compared to recommended 
levels, they still assume doses from wall mounted systems should be nil ${ }^{27}$.

In 2018 Rottke et. al aimed to show the expected distribution of scatter radiation from handheld devices and therefore evidence for regulations to reduce the size of the required controlled area. According to their study design and using the NOMAD ${ }^{\mathrm{TM}}$ Pro2, they concluded handheld $\mathrm{x}$-ray systems cannot be rated disadvantageous to wall-mounted systems and that the actual CA was notably smaller than (German) regulations ${ }^{10}$. They recommend the use of rectangular collimation, but many operators refrained from using it and decided to use circular collimation in their study. Another limitation in their study design was the calculation of air kerma. Air kerma does not represent a measured body absorbed dose or a calculated effective dose which limits comparability to more current studies which use the radiation protection measurements of equivalent and effective dose.

Zenobio and colleagues evaluated the DIOX intraoral portable device for image quality and radioprotection criteria and found the device was safe for use and produced image quality equivalent to two conventional wall-mounted systems ${ }^{28}$. When simulating the exposure of a maxillary periapical radiograph, they showed the operator's gonadal region without the acrylic shield received the highest estimated equivalent dose of $0.057 \mathrm{mSv} /$ week which was almost 20 times lower than established allowable level. The regions of the salivary glands and oral mucosa were the organs with the highest absorbed dose in the patient. In 2019, Smith et. al also calculated air kerma measurements from five different handheld x-rays devices at numerous spatial positions and concluded there is potential for increased radiation risk to the operator, therefore handheld x-ray devices should only be used on a stand ${ }^{29}$.

Hoogeveen and colleagues concluded safety issues from handheld devices are resolved and focused solely on image quality aspects in their 2019 study. Intraoral radiographs of four 
regions (bitewing, upper molar, lower molar and upper anterior) in five mannequins were obtained using the NOMAD ${ }^{\mathrm{TM}}$ Pro 2 handheld device and a wall-mounted unit. Their study design found aiming precision proved similar for both systems although individuals may perform better using one or the other modality ${ }^{30}$. They also mentioned that aiming precision is not a limiting factor for image quality. Of note, this study design did include rectangular collimation.

The literature on handheld x-ray devices varies greatly in study design and methodology. The majority of studies have been done using a model of the NOMAD ${ }^{\mathrm{TM}}$ handheld device, and very limited research is found on the other available devices. Some studies only evaluate dosimetry or image quality while a few have attempted to evaluate both. In addition, there is no consistent trend for dosimetry methodology, with ionization chambers, personal dosimeters, and thermoluminescent (TLD) and optically stimulated luminescent (OSL) dosimeters found in handheld research. The use of ionization chambers can create unknown variables due to different sizes of chambers and positioning which could result in different air kerma measurements for the same conditions. The value of air kerma alone in modern studies is also questionable since the ICRP has already determined effective dose is the preferred unit for comparing different radiographic examinations ${ }^{12}$ and the discussion of dose without context is fairly meaningless, especially to non-radiology specialists. Variability with the threshold of detection for personal dosimeters also exists. The thresholds are $10 \mu \mathrm{Sv}$ and $100 \mu \mathrm{Sv}$ for optically stimulated luminescent and thermoluminscent dosimeters respectively.

While many different phantom models have been used, few studies have used the gold standard anthropomorphic phantom to simulate patient x-ray absorption and backscatter. 
Exposure parameters and operating procedures vary in the literature. Different exposure parameters affect the $\mathrm{mAs}$ and therefore exposure and resultant dose. A majority of studies have operated these devices according to manufacturer's recommendations with regard to positioning, and a few have attempted to showcase the worst-case scenario positioning seen with patients in the supine position. Furthermore, to this author's knowledge, no studies have evaluated the effects of rectangular collimation with handheld devices specifically or discussed handheld devices used for full mouth series examinations on children. In addition, no studies as of yet have attempted to show a more realistic example of how these devices are used in general dentistry when taking a full mouth series (FMX) of images. 


\section{CHAPTER III}

\section{METHODS}

This study was designed to compare two handheld x-ray devices and one conventional wall-mounted x-ray source using both circular and rectangular collimator attachments that are currently being used in dental radiographic practice. When exposing radiographs, it is important to keep the dose as low as reasonably achievable (ALARA) while simultaneously producing a diagnostic image. Therefore, the design of this study included a dosimetry component and a technical component.

\section{$\underline{\text { Part A: Dosimetry Component }}$}

\section{Intraoral X-ray Systems and Collimator Attachments}

\section{Devices}

1. NOMAD ${ }^{\mathrm{TM}}$ Pro2 (handheld)

2. Xray2go (handheld)

3. FOCUS ${ }^{\mathrm{TM}}$ Instrumentarium (conventional wall-mounted)

\section{Modalities}

- NOMAD $^{\mathrm{TM}}$ Pro2 with circular collimation

- NOMAD $^{\mathrm{TM}}$ Pro2 with rectangular collimation

- Xray2go with circular collimation

- FOCUS ${ }^{\mathrm{TM}}$ Instrumentarium with circular collimation

- FOCUS ${ }^{\mathrm{TM}}$ Instrumentarium with rectangular collimation

Dose associated with five modalities was measured. The NOMAD ${ }^{\mathrm{TM}}$ Pro2, hereafter referred to as "NOMAD"M," circular technique utilized the $6 \mathrm{~cm}$ diameter original manufacturer equipment (OEM) circular collimator attachment with a $20 \mathrm{~cm}$ source to collimator end distance (Figure 3.1). The NOMAD ${ }^{\mathrm{TM}}$ rectangular technique utilized the $3 \times 4 \mathrm{~cm}$ OEM rectangular 
collimator attachment fitted over the circular collimator end resulting in a $23 \mathrm{~cm}$ source to collimator end distance (Figure 3.2). The Xray2go circular technique utilized the $5.3 \mathrm{~cm}$ diameter OEM circular collimator with a $20 \mathrm{~cm}$ source to collimator end distance (Figure 3.3). The FOCUS ${ }^{\mathrm{TM}}$ Instrumentarium, hereafter referred to as "FOCUS"T," circular technique utilized the $6 \mathrm{~cm}$ diameter OEM circular collimator with a $22.9 \mathrm{~cm}$ source to collimator end distance (Figure 3.4). The FOCUS ${ }^{\mathrm{TM}}$ rectangular technique utilized the $3.5 \times 4.5 \mathrm{~cm}$ OEM rectangular collimator with a $30.5 \mathrm{~cm}$ source to collimator end distance (Figure 3.5). Backscatter shields were in place for all handheld modalities. Technical specifications for all modalities tested are presented in Table 3.1.

A subjective normalization procedure was performed due to the wide variation in technical specifications seen for all modalities. Exposure settings used in this study were optimized for each modality for acquisition with a Schick 33 direct digital complementary metal oxide semiconductor (CMOS) sensor (Dentsply, Sirona). Step wedge images were assessed and a consensus among expert observers established the lowest exposure time possible for each modality which still produced a diagnostically acceptable radiographic image. Optimized exposure parameters and corresponding images are found in Figure 3.6.

Following the subjective normalization procedure, a separate objective normalization procedure was performed to normalize dose for the beam energy of each modality. Using a benchtop experiment, three OSL dosimeters were exposed at the posterior optimized exposure time for each modality and the mean absorbed doses were calculated. Based on mean absorbed dose measured, each modality was compared as a percentage of the conventional wall-mounted source with rectangular collimation, which was set to $100 \%$. This percentage was used as a cofactor to normalize the effective doses calculated in the study. Study effective doses and 
normalized effective doses were compared for all modalities.

\section{Phantoms}

Adult dosimetry was acquired using an average adult tissue-equivalent phantom (ATOMmax Model 711HN - CIRS Inc., Norfolk, VA) (Figure 3.7). The phantom is sectioned in $25 \mathrm{~mm}$ thick axially oriented slices which permit access to specific tissues and anatomical locations of interest. Slices are modified to accept optically stimulated luminescent (OSL) dosimeter chips at these internal and external sites (Appendix A). During the imaging process, the phantom was oriented so that the section planes were approximately parallel to the floor. Dosimeters were positioned at 24 anatomical locations corresponding to tissues of interest seen in Appendix B.

Child dosimetry was acquired using a tissue equivalent phantom simulating the anatomy of a 10-year old child (ATOMmax Model 706 HN, CIRS Inc., Norfolk, VA) (Figure 3.8). The child phantom is divided into $25 \mathrm{~mm}$ thick axially oriented slices and dosimeters were positioned at 24 anatomical locations corresponding to tissues of interest (Appendix B).

\section{Dosimeters and Reader}

Dosimetry was recorded using optically stimulated luminescent dosimeter chips (Nanodot, Landauer, Inc., Glenwood, IL) (Figure 3.9). Optically stimulated luminescent dosimeters respond to ionizing radiation by storing energy proportional to the amount of $\mathrm{x}$-ray energy in the exposure. Each dosimeter is encased in a light-tight plastic holder measuring approximately $1 \mathrm{~mm} \times 10 \mathrm{~mm} \times 10 \mathrm{~mm}$. This case prevents loss of energy through stimulation by ambient light. Sets of 24 dosimeters were grouped and coded for identification. Multiple dosimeter sets were used during this study. Each set was cleared of stored energy using an LED light source (drafting pad) for a minimum of twenty-four hours prior to establishing baseline 
reading. Dosimeters used in this study were read with an OSL dosimeter reader (MicroStarii, Landauer, Inc., Glenwood, IL) (Figure 3.10). The reader was calibrated initially with a set of dosimeters supplied by the manufacturer that had been exposed to known amounts of energy from an $80 \mathrm{kVp} \mathrm{x}$-ray source. Reader performance was checked before each use. Photon counts were converted to dose using an energy specific conversion factor reflecting the 60 and $70 \mathrm{kVp}$ sources that were used throughout the study. All dosimetry was done by the investigator.

\section{Adult Dosimetry Procedure}

Eighteen projections simulating an adult full mouth series (FMX) and constituting one dosimeter run, were exposed using each modality on the adult ATOMmax phantom. Exposure parameters used were $70 \mathrm{kV} / 7 \mathrm{~mA}$ and 0.04 seconds for anterior projections and .05 seconds for posterior projections for the FOCUS ${ }^{\mathrm{TM}}$ conventional wall-mounted unit with circular collimation, $70 \mathrm{kV} / 7 \mathrm{~mA}$ and 0.063 seconds for anterior projections and .08 seconds for posterior projections for the FOCUS ${ }^{\mathrm{TM}}$ conventional wall-mounted unit with rectangular collimation, $60 \mathrm{kV} / 2.5 \mathrm{~mA}$ and 0.1 seconds for anterior projections and 0.13 seconds for posterior projections for the NOMAD ${ }^{\mathrm{TM}}$ handheld device with circular collimation and rectangular collimation, and $60 \mathrm{kV} / 2 \mathrm{~mA}$ and 0.09 seconds for anterior projections and 0.12 seconds for posterior projections for the Xray2go handheld device with circular collimation. For each dosimeter run, the simulated FMX was repeated 10 times (180 exposures) to provide a more reliable measure of energy in the dosimeters at the peripheries of the exposure areas. Dosimeter readings were then divided by 10 to determine the dose per single FMX. Each dosimetry run was repeated three times with the same modality using fresh sets of dosimeters to account for operator variability and the average dose of the three runs was calculated for each modality. 
To the best of the investigator's ability, exposures were made with all modalities using the same distance from end of the collimator cone to the phantom which was meant to represent an actual separation that would occur if a beam-aiming device could be used. In addition, to the best of the investigator's ability, exposures were made with all modalities using the same projection position and vertical and horizontal angulations recommended for acquiring an FMX with a conventional wall-mounted source while keeping the phantom oriented so the section planes were approximately parallel to the floor. These angulations and exposure time parameters are listed in Table 3.2. This positioning of the handheld devices constitutes the exploratory technique in this study and is in contrast with both handheld device manufacturer's recommendations that the patient tilt their head to accommodate positioning the device so that the x-ray beam remains parallel to the floor and perpendicular to the operator. This study was specifically designed in order to evaluate the "real world" radiation dose for the patient and operator if the device is maneuvered the same way as a typical intraoral examination made with a conventional wall-mounted source with a patient seated upright in a chair. It is assumed this positioning technique would be most habitual and comfortable for the operator which should limit image re-takes.

\section{Child Dosimetry Procedure}

Twelve projections simulating a child full mouth series (FMX) and constituting one dosimeter run were exposed using each modality on the child phantom. Exposure parameters used were $70 \mathrm{kV} / 7 \mathrm{~mA}$ and 0.032 seconds for anterior projections and 0.04 seconds for posterior projections for the FOCUS ${ }^{\mathrm{TM}}$ conventional wall-mounted unit with circular collimation, $70 \mathrm{kV} / 7$ $\mathrm{mA}$ and 0.05 seconds for anterior projections and 0.063 seconds for posterior projections for the FOCUS $^{\mathrm{TM}}$ conventional wall-mounted unit with rectangular collimation, $60 \mathrm{kV} / 2.5 \mathrm{~mA}$ and 
0.09 seconds for anterior projections and 0.12 seconds for posterior projections for the NOMAD ${ }^{\mathrm{TM}}$ handheld device with circular collimation and rectangular collimation, and $60 \mathrm{kV} / 2$ $\mathrm{mA}$ and 0.08 seconds for anterior projections and 0.11 seconds for posterior projections for the Xray2go handheld device with circular collimation. For each dosimeter run, the simulated FMX was repeated 10 times (120 exposures) to provide a more reliable measure of energy in the dosimeters at the peripheries of the exposure areas. Dosimeter readings were then divided by 10 to determine the dose per single FMX. Each dosimetry run was repeated three times with the same modality using fresh sets of dosimeters to account for operator variability and the average dose of the three runs was calculated for each modality.

Similar to adult phantom acquisitions, child exposures were made with all modalities using the same end of collimator cone to phantom distance, projection position and vertical and horizontal angulations as described for the adult procedure using reduced exposure settings and 12 projections per FMX. Angulations and child exposure time parameters are listed in Table 3.3. The dosimetry acquisition matrix for the entire is found in Table 3.4.

\section{Operator Dosimetry Procedure}

Operator dosimetry was acquired using OSL dosimeter chips affixed to four locations of interest: thyroid, breast, groin area and handheld device trigger hand. One dosimeter was taped to each location on a lead apron worn by the operator and to the device trigger hand location for each dosimeter run during the previously described adult and child dosimetry procedures. Since simulated FMX exams were repeated 10 times per run, measured doses from the operator dosimeters were divided by 10 to achieve the average dose per FMX.

A supplemental operator dosimetry procedure was also performed for comparison purposes where the handheld modalities were operated according to the manufacturer's 
instructions (keeping the x-ray beam parallel to the floor and perpendicular to the operator). The adult phantom was tilted in order to accommodate this position. One simulated FMX run was completed using each handheld modality and the same exposure times used for the adult dosimetry procedure. Optically stimulated luminescent dosimeter chips were applied as previously mentioned above. Since simulated FMX exams were repeated 10 times per run, measured doses from the operator dosimeters were divided by 10 to achieve the average dose per FMX.

\section{Dose Calculations and Adjustments}

Effective dose was the primary outcome variable of this study. It is arrived at only by calculation and its value expresses the relative risk of human tissue detriment from ionizing radiation. Doses from OSL dosimeters at specific locations within the tissue or organ were averaged to express the average tissue-absorbed dose in micrograys ( $\mu \mathrm{Gy}$ ). The products of these values and the estimated percentages of tissue or organ irradiated in the ATOMax phantom for an FMX and the radiation weighting factor for $\mathrm{x}$-rays were used to calculate the equivalent dose (Appendix C). Effective dose, expressed in $\mu \mathrm{Sv}$, was calculated by using the equation $\mathrm{E}=$ $\Sigma W_{\mathrm{T}} \times \mathrm{HT}$ and applying 2007 ICRP tissue weighting factors ${ }^{2}$, where effective dose (E) is the sum of the products of the tissue-weighting factor $\left(W_{\mathrm{T}}\right)$, (Appendix $\left.\mathrm{D}\right)$ and the equivalent $\operatorname{doses}^{2,14}$.

\section{Investigator}

The investigator was an oral and maxillofacial radiology resident and the sole operator for all exposures. 


\section{Statistical Analysis}

Dosimetry data was analyzed using Analysis of Variance (ANOVA) and Tukey Honestly Significant Difference (HSD) post-hoc analysis to assess differences among mean patient effective doses and operator doses for all modalities.

\section{Part B: Technical Performance and Image Quality}

\section{Investigator}

The investigator was an oral and maxillofacial radiology resident and the sole operator for all exposures. The investigator was trained on each device according to the manufacturer's instructions. The NOMAD ${ }^{\mathrm{TM}}$ and the $\mathrm{X}-$ Ray2Go provide a training module that was viewed prior to use of the handheld devices and the recommended post-test was taken to achieve a perfect score.

\section{Modalities}

Images were produced with the FOCUS ${ }^{\mathrm{TM}}$ conventional wall-mounted source with circular and rectangular collimation, the $\mathrm{NOMAD}^{\mathrm{TM}}$ handheld device with circular and rectangular collimation and the X-Ray2Go handheld device with circular collimation, the only collimator shape available for this device. Technical performance, diagnostic acceptability and image quality were evaluated.

\section{Receptors}

All radiographs were exposed using a Schick 33 direct digital CMOS sensor. A size-2 sensor was used for all central, molar and bitewing exposures. A total of four projections (upper right molar periapical, molar bitewing, lower right molar periapical and maxillary central periapical) constituted one series of images for the technical performance segment of this study. 
These four projections were chosen to adequately represent the variation of images necessary to complete a full mouth series of radiographs.

\section{Equipment}

Handheld device exposures were made using the NOMAD ${ }^{\mathrm{TM}}$ handheld device and the Xray2go handheld device. The NOMAD ${ }^{\mathrm{TM}}$ was used with both circular and rectangular collimation. Xray2go exposures were made using circular collimation. Conventional wallmounted source exposures were made using the FOCUS ${ }^{\mathrm{TM}}$ source with both circular and rectangular collimation. All exposures were made with the same optimized parameters for an adult for each modality that were used in Part A of the study.

Nine Dental X-ray Teaching and Training Replicas (DXTTRs) (DENTSPLY Rinn, Elgin, IL) were identified for use in the study. Each DXTTR is designed with natural teeth and human skulls. Selection of the DXTTRs was based on optimal, mechanical and operational conditions.

\section{5: Technical Performance Procedure}

The investigator exposed one four image series (upper right molar periapical, molar bitewing, lower right molar periapical and maxillary central periapical) using each of the five modalities on all nine DXTTRs (45 series total) utilizing the Extension Cone Paralleling (XCP) receptor-holding device (DENTSPLY Rinn, Elgin, IL). There was unlimited time to complete the images and the investigator treated the radiographs as if they were imaging a live patient. Images were assessed based on presence or absence of minor and major errors.

\section{Evaluator Criteria and Image Assessment}

One experienced evaluator assessed all study images for technical quality and presence of imaging errors. Intra-rater reliability was assessed by re-evaluating $10 \%$ of the images. Images were stored in the investigator's Electronic Patient Record. 
All study images were blinded to the evaluator based on DXTTR and x-ray device/collimator combination. The images were evaluated for the presence of horizontal angulation error, vertical angulation error, cone cut and motion based on predetermined criteria (Appendix E). Minor errors are represented by the presence of the error, but the intended anatomic structures are displayed in the image. A major error in diagnostic quality was based on the absence of specified anatomic structures and would require a re-take.

\section{Image Quality Procedure}

A 16-group line pair per millimeter (LP) test tool with a range of resolutions from 5 to 20-line pairs per millimeter (Model 07-555, Nuclear Associates, Division of Victoreen, Carle Place, NY) was used to assess range of spatial resolution. One radiographic image was made with each modality using the line-pair phantom held in a jig to reduce the likelihood of motion artefacts and a $2.5 \mathrm{~cm}$ acrylic slab used to simulate actual source to object and object to image detector distances. Three experienced evaluators assessed all images. All study images were blinded to the evaluators based on x-ray device/collimator combination. Images were stored in the investigator's Electronic Patient Record.

\section{8: Statistical Analysis}

A bivariate analysis and chi-square statistics were used to report number and location of errors by modality. Descriptive statistics were used to report average number of observed line pairs for all observers and the standard deviation per modality

9: IRB Study \#:18-1496

The protocol for this study was submitted for review by the Office of Human Research and it was determined the submission did not constitute human subjects research as defined 
under federal regulations [45 CFR 46.102 (d or f) and 21 CFR 56.102 (c)(e)(1)] and did not require IRB approval. 


\section{CHAPTER III FIGURES}

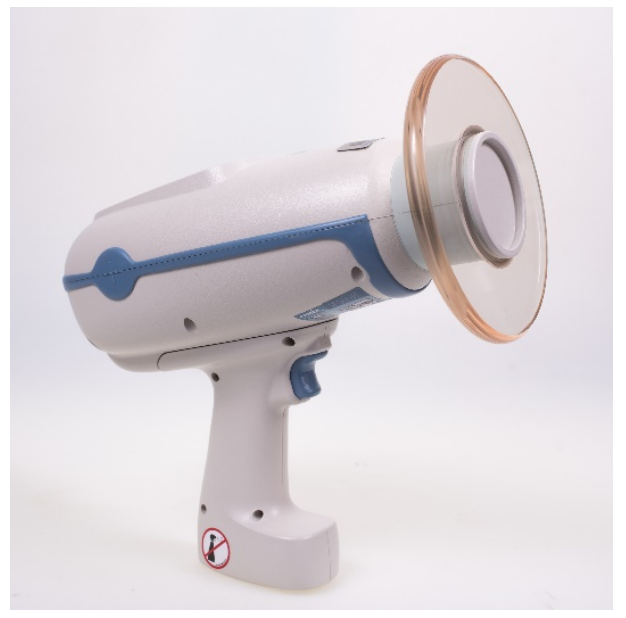

Figure 3.1: $\mathrm{NOMAD}^{\mathrm{TM}}$ Circular Collimator

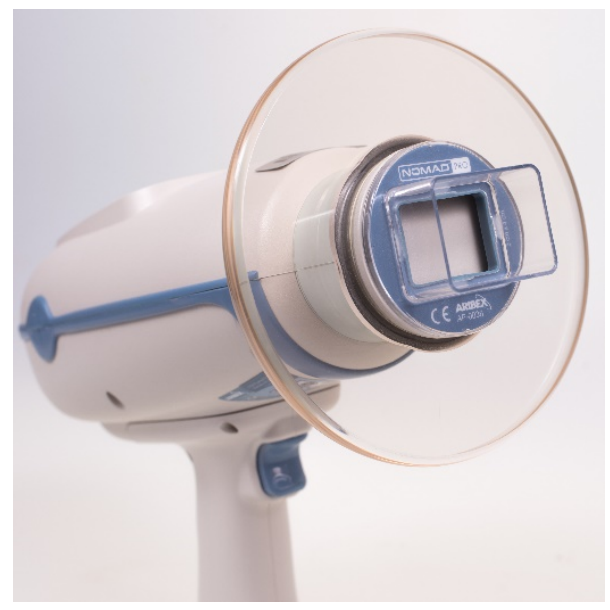

Figure 3.2: $\mathrm{NOMAD}^{\mathrm{TM}}$ Rectangular Collimator 


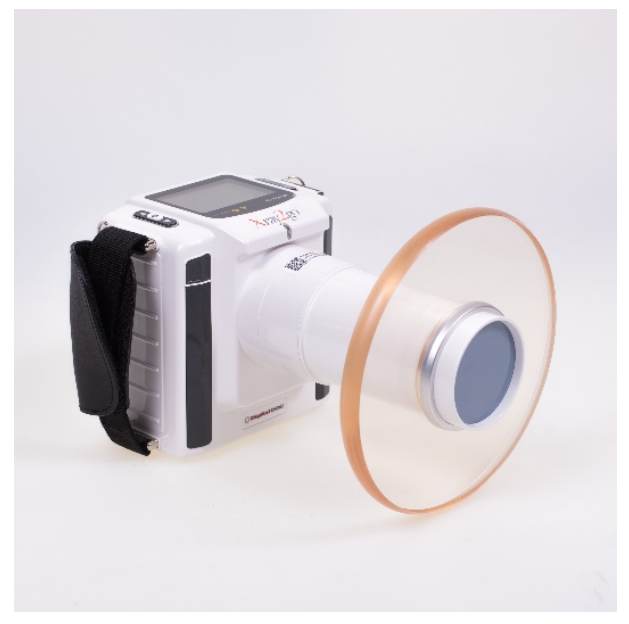

Figure 3.3: Xray2go Circular Collimator

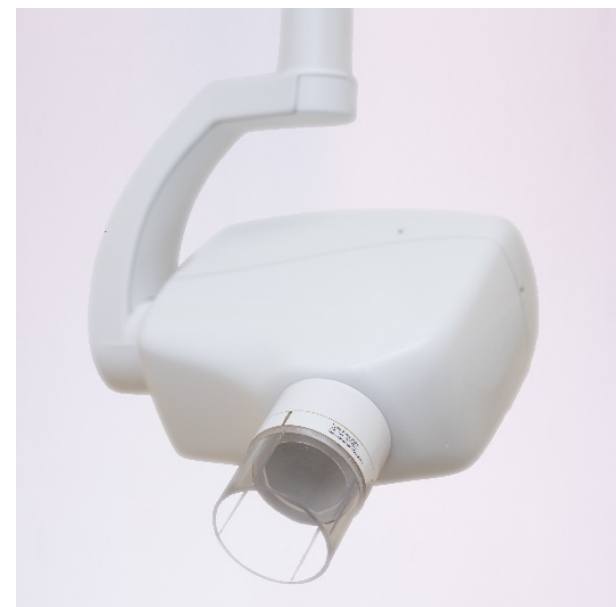

Figure 3.4: FOCUS ${ }^{\mathrm{TM}}$ Circular Collimator 


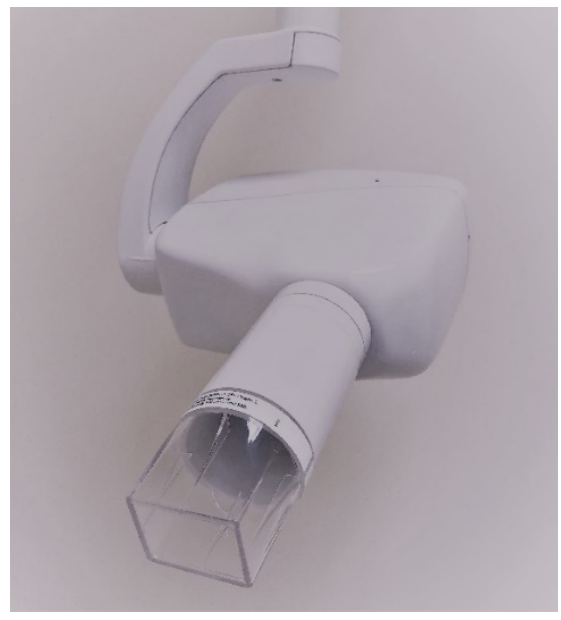

Figure 3.5: FOCUS ${ }^{\mathrm{TM}}$ Rectangular Collimator

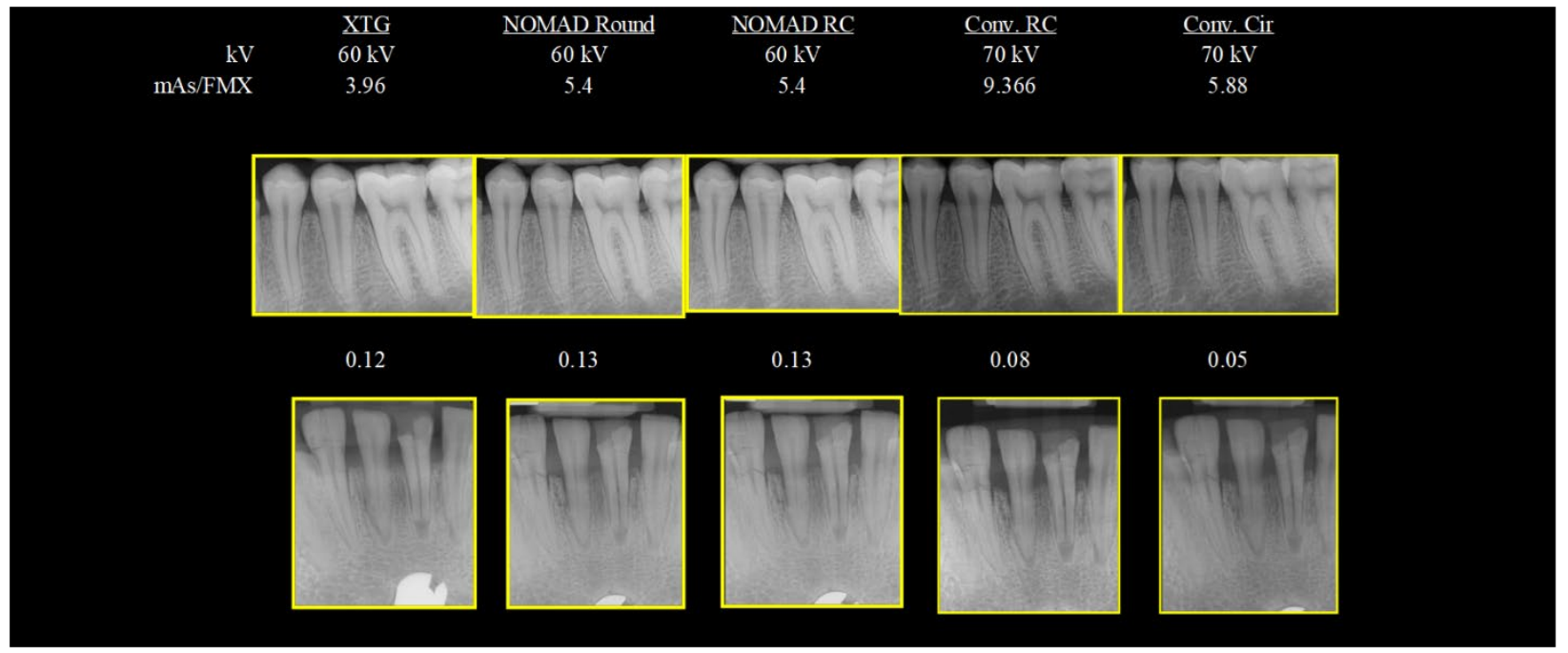

Figure 3.6: Adult Optimized Exposure Parameters and Corresponding Images 


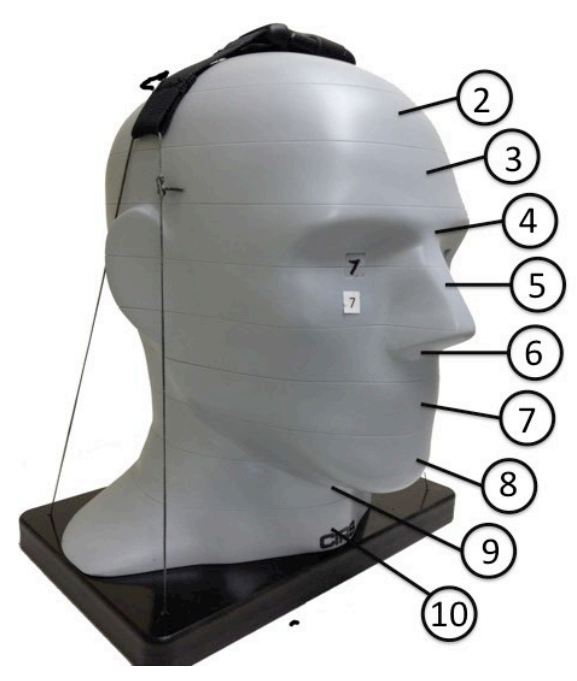

Figure 3.7: Average Adult Tissue-Equivalent Phantom (ATOMmax Model 711HN - CIRS Inc, Norfolk, VA)

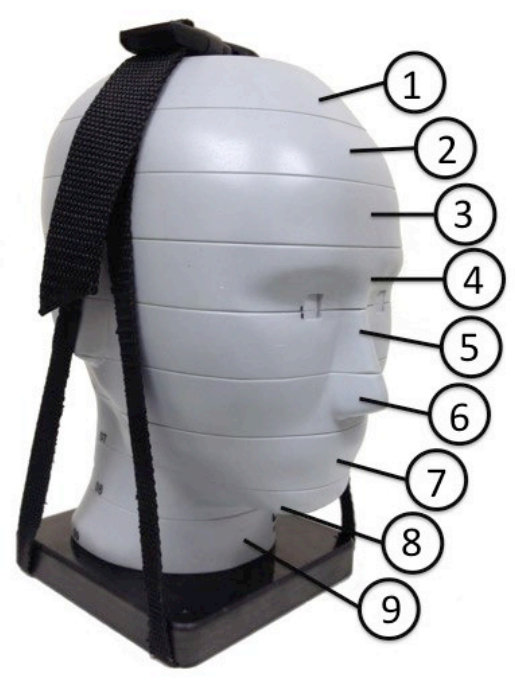

Figure 3.8: Average Child Tissue-Equivalent Phantom (ATOMmax Model 706 HN - CIRS Inc., Norfolk, VA) 


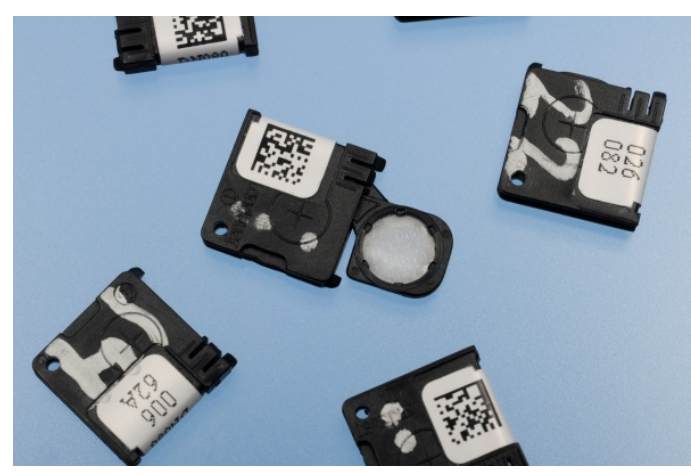

Figure 3.9: OSL Dosimeters (Nanodot, Landauer, Inc., Glenwood, IL)

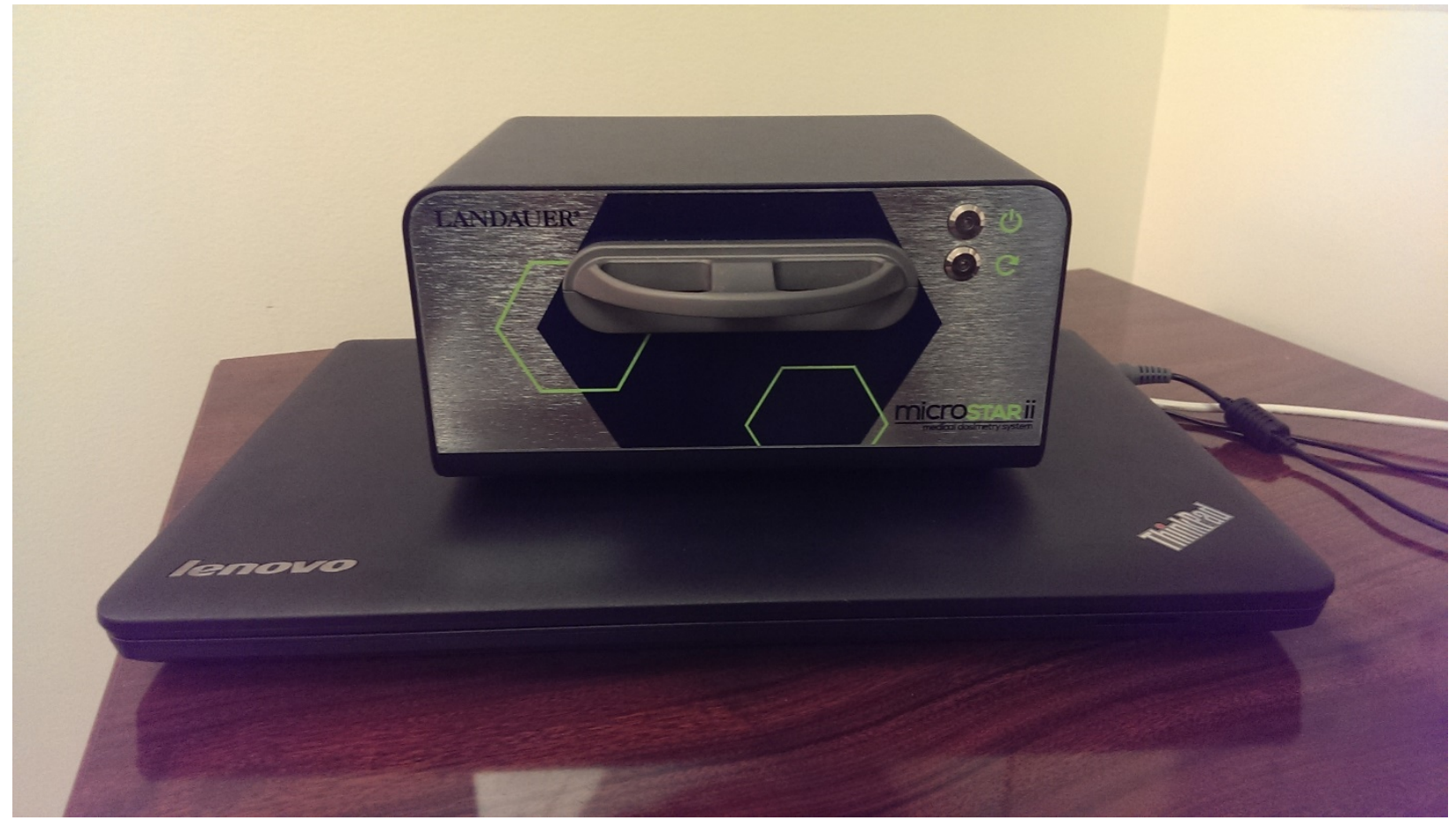

Figure 3.10: OSL Dosimeter Reader (MicroStarii, Landauer, Inc., Glenwood, IL) 


\section{CHAPTER III TABLES}

Table 3.1: Specifications of X-ray Systems

\begin{tabular}{|c|c|c|c|c|c|c|c|}
\hline & Fixed tube-voltage ( $\mathrm{kVp}$ ) & $\begin{array}{c}\text { Fixed tube } \\
\text { current } \\
(\mathrm{mA})\end{array}$ & $\begin{array}{c}\text { Collimator cone } \\
\text { diameter }(\mathrm{cm})\end{array}$ & $\begin{array}{c}\text { Source to } \\
\text { collimator end } \\
\text { distance }(\mathrm{cm})\end{array}$ & $\begin{array}{c}\text { Focal spot size } \\
(\mathrm{mm})\end{array}$ & $\begin{array}{c}\text { Diameter of } \\
\text { backscatter shield } \\
(\mathrm{cm})\end{array}$ & $\begin{array}{c}\text { Mamufacturer specified } \\
\text { total filtration ( } \mathrm{mm} \mathrm{Al} \\
\text { equivalent) }\end{array}$ \\
\hline $\begin{array}{l}\text { Xray2go handheld } \\
\text { (Digital Doc LLC, El Dorado } \\
\text { Hills, CA) }\end{array}$ & 60 (constant potential) & 2 & 5.3 circular & 20 & 0.8 & 15.24 & 1.6 \\
\hline $\begin{array}{l}\text { NOMAD }{ }^{\mathrm{TM}} \text { Pro } 2 \text { handheld } \\
\text { (KaVo Kerr, Brea, CA) }\end{array}$ & 60 (constant potential) & 2.5 & $\begin{array}{c}6 \text { (circular) } \\
3 \times 4 \text { (rectangular) }\end{array}$ & $\begin{array}{l}20 \\
23\end{array}$ & 0.4 & 15.5 & $\geq 1.5$ \\
\hline $\begin{array}{l}\text { Instrumentarium FOCUS } \\
\text { wall-mounted } \\
\text { (KaVo Kerr, Brea, CA) }\end{array}$ & 70 (constant potential) & 7 & $\begin{array}{c}6 \text { (circular) } \\
3.5 \times 4.5 \text { (rectangular) }\end{array}$ & $\begin{array}{l}22.9 \\
30.5\end{array}$ & 0.7 & $\mathrm{~N} / \mathrm{A}$ & 2 \\
\hline
\end{tabular}

Table 3.2: Adult Intraoral Imaging Study Parameters

\begin{tabular}{|c|c|c|c|c|c|c|c|c|}
\hline Image Type & Area & Vertical & Horizontal & $\begin{array}{l}\text { Exposure time } \\
\text { (sec) Xray2go }\end{array}$ & $\begin{array}{c}\text { Exposure time }(\mathrm{sec}) \\
\text { NOMAD }{ }^{T M} \text { Circular and } \\
\text { Rect. Collimation }\end{array}$ & $\begin{array}{c}\text { Exposure time (sec) } \\
\text { FOCUS }{ }^{T M} \text { Circular } \\
\text { Collimation } \\
\end{array}$ & $\begin{array}{c}\text { Exposure time }(\mathrm{sec}) \\
\text { FOCUS }{ }^{T M} \text { Rect. } \\
\text { Collimation }\end{array}$ & No. of Images \\
\hline PA maxillary & Molar & $25^{\circ}$ & $80^{\circ}$ & 0.12 & 0.13 & 0.05 & 0.08 & 2 \\
\hline PA maxillary & Premolar & $25^{\circ}$ & $75^{\circ}$ & 0.12 & 0.13 & 0.05 & 0.08 & 2 \\
\hline PA maxillary & Canine-lateral & $45^{\circ}$ & $25^{\circ}$ & 0.09 & 0.1 & 0.04 & 0.063 & 2 \\
\hline PA maxillary & Centrals & $45^{\circ}$ & $0^{\circ}$ & 0.09 & 0.1 & 0.04 & 0.063 & 1 \\
\hline PA mandibular & Molar & $0^{\circ}$ & $80^{\circ}$ & 0.12 & 0.13 & 0.05 & 0.08 & 2 \\
\hline PA mandibular & Premolar & $-15^{\circ}$ & $75^{\circ}$ & 0.12 & 0.13 & 0.05 & 0.08 & 2 \\
\hline PA mandibular & Canine-lateral & $-20^{\circ}$ & $25^{\circ}$ & 0.09 & 0.1 & 0.04 & 0.063 & 2 \\
\hline PA mandibular & Centrals & $-20^{\circ}$ & $0^{\circ}$ & 0.09 & 0.1 & 0.04 & 0.063 & 1 \\
\hline BW & Molar & $10^{\circ}$ & $80^{\circ}$ & 0.12 & 0.13 & 0.05 & 0.08 & 2 \\
\hline BW & Premolar & $10^{\circ}$ & $75^{\circ}$ & 0.12 & 0.13 & 0.05 & 0.08 & 2 \\
\hline mAs/FMX & & & & 3.96 & 5.4 & 5.88 & 9.37 & 18 Total Images \\
\hline
\end{tabular}

Table 3.3: Child Intraoral Imaging Study Parameters

\begin{tabular}{|c|c|c|c|c|c|c|c|c|}
\hline Image Type & Area & Vertical & Horizontal & $\begin{array}{l}\text { Exposure time } \\
\text { (sec) Xray2go }\end{array}$ & $\begin{array}{c}\text { Exposure time (sec) } \\
\text { NOMAD }{ }^{T M} \text { Circular and } \\
\text { Rect. Collimation }\end{array}$ & $\begin{array}{c}\text { Exposure time (sec) } \\
\text { FOCUS }{ }^{T M} \text { Circular } \\
\text { Collimation }\end{array}$ & $\begin{array}{c}\text { Exposure time (sec) } \\
\text { FOCUS }{ }^{T M} \text { Rect. } \\
\text { Collimation }\end{array}$ & No. of Images \\
\hline PA maxillary & Molar & $25^{\circ}$ & $80^{\circ}$ & 0.11 & 0.12 & 0.04 & 0.063 & 0 \\
\hline PA maxillary & Premolar & $25^{\circ}$ & $75^{\circ}$ & 0.11 & 0.12 & 0.04 & 0.063 & 2 \\
\hline PA maxillary & Canine-lateral & $45^{\circ}$ & $25^{\circ}$ & 0.08 & 0.09 & 0.032 & 0.05 & 2 \\
\hline PA maxillary & Centrals & $45^{\circ}$ & $0^{\circ}$ & 0.08 & 0.09 & 0.032 & 0.05 & 1 \\
\hline PA mandibular & Molar & $0^{\circ}$ & $80^{\circ}$ & 0.11 & 0.12 & 0.04 & 0.063 & 0 \\
\hline PA mandibular & Premolar & $-15^{\circ}$ & $75^{\circ}$ & 0.11 & 0.12 & 0.04 & 0.063 & 2 \\
\hline PA mandibular & Canine-lateral & $-20^{\circ}$ & $25^{\circ}$ & 0.08 & 0.09 & 0.032 & 0.05 & 2 \\
\hline PA mandibular & Centrals & $-20^{\circ}$ & $0^{\circ}$ & 0.08 & 0.09 & 0.032 & 0.05 & 1 \\
\hline BW & Molar & $10^{\circ}$ & $80^{\circ}$ & 0.11 & 0.12 & 0.04 & 0.063 & 0 \\
\hline BW & Premolar & $10^{\circ}$ & $75^{\circ}$ & 0.11 & 0.12 & 0.04 & 0.063 & 2 \\
\hline mAs/FMX & & & & 2.28 & 3.15 & 3.02 & 4.75 & 12 Total Images \\
\hline
\end{tabular}


Table 3.4: Dosimetry Acquisition Study Matrix

NOMAD ${ }^{\mathrm{TM}}$ Pro2 handheld device \& circular collimation

NOMAD ${ }^{\mathrm{TM}}$ Pro2 handheld device \& rectangular collimation

Modalities (5): $\quad$ Xray2go handheld device \& circular collimation

FOCUS $^{\mathrm{TM}}$ conventional wall-mounted source \& circular collimation

FOCUS $^{\mathrm{TM}}$ conventional wall-mounted source \& rectangular collimation

Phantom sizes (2):

adult

10-year old child

Repitition of dosimeter runs: 3

\begin{tabular}{ll}
\hline Total dosimeter runs: & 30 \\
\hline Adult FMX: & 18 image series (6 vertical anterior PAs, 8 horizontal posterior PAs, 4 BWs) \\
\hline Child FMX: & 12 image series (6 vertical anterior P As, 4 horizontal posterior PAs, 2 BWs) \\
\hline $\begin{array}{l}\text { FMX Exposures per } \\
\text { dosimeter run: }\end{array}$ & 10 \\
\hline Total FMXs for projects: & 300 \\
\hline Total Exposures: & 4500 \\
\hline ANOVA outcome variable: & Effective dose \\
\hline Experimental variables: & Modality, phantom \\
\hline
\end{tabular}




\section{CHAPTER IV}

\section{RESULTS}

\section{Part A: Dosimetry Component Results}

\section{Adult Dosimetry Results}

Figure 4.1 displays the average adult effective doses $(\mu \mathrm{Sv})$ from all five modalities. The lowest dose achieved was using the NOMAD ${ }^{\mathrm{TM}}$ with the OEM rectangular collimator attachment $(6.87 \mu \mathrm{Sv})$. Mean (SD) FMX effective dose was statistically significantly less for handheld techniques with circular collimation than for the FOCUS ${ }^{\mathrm{TM}}$ conventional wall-mounted source with circular collimation $(\mathrm{p}<.0001)$. All effective doses using rectangular collimation were statistically significantly less than all circular collimation techniques $(p<.0001)$. Statistically significant differences were found for all modality combinations except the NOMAD ${ }^{\mathrm{TM}}$ with circular collimation and the Xray2Go $(\mathrm{p}=.8329)$.

Figure 4.2 displays the average normalized adult effective doses $(\mu \mathrm{Sv})$ from all five modalities. Normalized effective doses using circular collimation were $30.4 \mu \mathrm{Sv}$ for the conventional wall-mounted source and $26.4 \mu \mathrm{Sv}$ for the Xray2go and the NOMAD ${ }^{\mathrm{TM}}$. The lowest normalized effective dose was from the $\mathrm{NOMAD}^{\mathrm{TM}}$ with rectangular collimation $(8.6$ $\mu \mathrm{Sv})$. The same statistical relationships seen with unadjusted effective doses were also seen with the normalized effective doses.

Table 4.1 shows the percent reduction in study effective dose that was achieved by each of the modalities when compared to the FOCUS ${ }^{\mathrm{TM}}$ conventional wall-mounted source. Handheld effective dose was at least $34 \%$ less than the effective dose using the FOCUS ${ }^{\mathrm{TM}}$ 
conventional wall-mounted source with circular collimation. Using the $\mathrm{NOMAD}^{\mathrm{TM}}$ with the OEM rectangular collimator attachment, the effective dose was $74 \%$ less than the FOCUS ${ }^{\mathrm{TM}}$ conventional wall-mounted source with circular collimation. Table 4.2 shows the percent reductions in surface area exposure achieved by all modalities compared to conventional with circular collimation.

\section{Child Dosimetry Results}

Figure 4.3 displays the average child effective doses $(\mu \mathrm{Sv})$ from all five modalities. The lowest doses achieved were using the FOCUS ${ }^{\mathrm{TM}}$ conventional wall-mounted source with rectangular collimation $(8.63 \mu \mathrm{Sv})$ and the $\mathrm{NOMAD}^{\mathrm{TM}}$ with the OEM rectangular collimator attachment $(10.17 \mu \mathrm{Sv})$ which were not statistically significantly different from each other. All effective doses using rectangular collimation were statistically significantly less than all circular collimation techniques $(p<.0001)$. Statistically significant differences were not found between the Xray2Go and the $\mathrm{NOMAD}^{\mathrm{TM}}$ with circular collimation, between the NOMAD ${ }^{\mathrm{TM}}$ with circular collimation and the FOCUS ${ }^{\mathrm{TM}}$ conventional wall-mounted source with circular collimation, or between the NOMAD ${ }^{\mathrm{TM}}$ with the OEM rectangular collimator attachment and the FOCUS ${ }^{\mathrm{TM}}$ conventional wall-mounted source with rectangular collimation.

Figure 4.4 displays the average normalized child effective doses $(\mu \mathrm{Sv})$ from all five modalities. Normalized effective doses using circular collimation were $29.4 \mu \mathrm{Sv}$ for the conventional wall-mounted source, $46.8 \mu \mathrm{Sv}$ for the Xray2go and $43.5 \mu \mathrm{Sv}$ for the NOMAD $^{\mathrm{TM}}$. The lowest dose achieved was using the conventional wall-mounted source with rectangular collimation $(8.6 \mu \mathrm{Sv})$. Statistical differences were not found between the Xray2Go and the NOMAD ${ }^{\mathrm{TM}}$ with circular collimation or the $\mathrm{NOMAD}^{\mathrm{TM}}$ with the OEM rectangular collimator attachment and the FOCUS ${ }^{\mathrm{TM}}$ conventional wall-mounted source with rectangular 
collimation.

Table 4.3 shows the percent reduction in effective dose that was achieved by each of the modalities when compared to the FOCUS ${ }^{\mathrm{TM}}$ conventional wall-mounted source. Using the NOMAD ${ }^{\mathrm{TM}}$ handheld device and the OEM rectangular collimator attachment, the effective dose was $60 \%$ less than the FOCUS ${ }^{\mathrm{TM}}$ conventional wall-mounted source with circular collimation. The FOCUS ${ }^{\mathrm{TM}}$ conventional wall-mounted source with rectangular collimation was $66 \%$ less than the conventional wall-mounted unit with circular collimation.

\section{Operator Dosimetry Results Adult Procedure}

Figure 4.5 displays the average operator dose ( $\mu \mathrm{Gy})$ per adult FMX to the four areas of interest for each of the handheld modalities using the exploratory positioning technique. Dose to the areas of the thyroid, chest and trigger hand were indistinguishable from ambient background levels for all handheld modalities $(\mathrm{p}<.0001)$. Operator dose to the groin area using the handheld devices with circular collimation was $4.1 \mu \mathrm{Gy}$ for the XRay2go and $2.4 \mu \mathrm{Gy}$ for the NOMAD ${ }^{\mathrm{TM}}$. This was significantly higher than the dose to the thyroid, chest and trigger hand for all handheld modalities as well as the dose to the groin area using the NOMAD ${ }^{\mathrm{TM}}$ with the OEM rectangular collimator attachment. Operator dose to the groin using the $\mathrm{NOMAD}^{\mathrm{TM}}$ with the OEM rectangular collimator attachment was $0.99 \mu \mathrm{Gy}$. This was higher but not statistically significantly different than the dose to the areas of the thyroid, chest and trigger hand for all handheld modalities.

Figure 4.6 compares the average operator dose $(\mu \mathrm{Gy})$ per adult FMX to the four areas of interest for each of the handheld modalities for the supplemental operator dosimetry procedure using the manufacturer recommended positioning technique. Exposure to all areas was reduced for all modalities using the manufacturer recommended positioning technique 
when compared to the exploratory positioning where the device position is variable throughout the FMX.

\section{Operator Dosimetry Results Child Procedure}

Figure 4.7 displays the average operator dose $(\mu \mathrm{Gy})$ per child FMX to the four areas of interest for each of the handheld modalities. Dose to the areas of the thyroid, chest and trigger hand were indistinguishable from ambient background levels for all handheld modalities $(\mathrm{p}<.0001)$. Operator dose to the groin area using the handheld devices with circular collimation was $1.81 \mu \mathrm{Gy}$ for the Xray2go and $1.29 \mu \mathrm{Gy}$ for the NOMAD ${ }^{\mathrm{TM}}$. These doses were significantly higher than the thyroid, chest and trigger from all handheld modalities as well as the dose to the groin area using the $\mathrm{NOMAD}^{\mathrm{TM}}$ with the OEM rectangular collimator attachment $(\mathrm{p}<.0001)$. Operator dose to the groin using the NOMAD ${ }^{\mathrm{TM}}$ with the OEM rectangular collimator attachment was $0.60 \mu \mathrm{Gy}$. This was higher than the dose to the areas of the thyroid, chest and trigger hand for all handheld modalities but only statistically significantly different from the thyroid and trigger hand using the $\mathrm{NOMAD}^{\mathrm{TM}}$ with $\mathrm{OEM}$ rectangular collimation attachment and the chest from the $\mathrm{NOMAD}^{\mathrm{TM}}$ using circular collimation.

\section{Part B: Technical Performance and Image Quality Results}

\section{Technical Performance Results}

Table 4.4 displays frequency and percentage of all technique errors (horizontal angulation error, vertical angulation error, cone cut or motion) by modality. There was not a statistically significant difference among modalities in terms of prevalence of error $(p=.07)$ although less errors occurred using circular collimation modalities when compared to rectangular collimation modalities. The lowest number of errors was seen with the Xray2Go 
handheld device with circular collimation and the greatest number of errors occurred with the conventional wall-mounted source with rectangular collimation. Of the rectangular collimation modalities, the NOMAD ${ }^{\mathrm{TM}}$ demonstrated less errors.

Table 4.5 displays the frequency and percentage of all technique errors by location in the mouth (upper right molar periapical, molar bitewing, lower right molar periapical or maxillary central periapical). There was a statistically significant difference among the locations in terms of proportion of error $(p<.0001)$. Twice as many errors were observed for both the maxillary and mandibular periapical location compared to the bitewing location, and three times as many errors were observed for both the maxillary and mandibular periapical location compared to the anterior location. However, when controlling for modality, the statistically significant difference among the locations in terms of proportion of error was no longer seen.

The intra-rater agreement was almost perfect (.94). Because of sparseness of data, statistical analysis of each technical error (horizontal angulation error, vertical angulation error, cone cut or motion) was not possible.

\section{Image Quality Results}

Table 4.6 shows the line pair phantom test observation results. The average number of line pairs observed by three expert observers from the five unique modalities are displayed. The number of line pairs observed ranged from 12.7 (SD 1.5) for the Xray2go, 13.3 (2.1) for the conventional wall-mounted source with circular and rectangular collimation, and 13.7 (1.5) for the NOMAD ${ }^{\mathrm{TM}}$ with circular and rectangular collimation. Coefficient of variation values range from $11-16 \%$ suggesting a small variation among interobserver agreement within devices. Observations for the conventional wall-mounted source with circular collimation line 
pair image resulted in the highest relative variation (16\%) compared to the four other devices (11-12\%). Higher line pair resolution favoring the NOMAD ${ }^{\mathrm{TM}}$ handheld $\mathrm{x}$-ray device was demonstrated. 


\section{CHAPTER IV FIGURES}

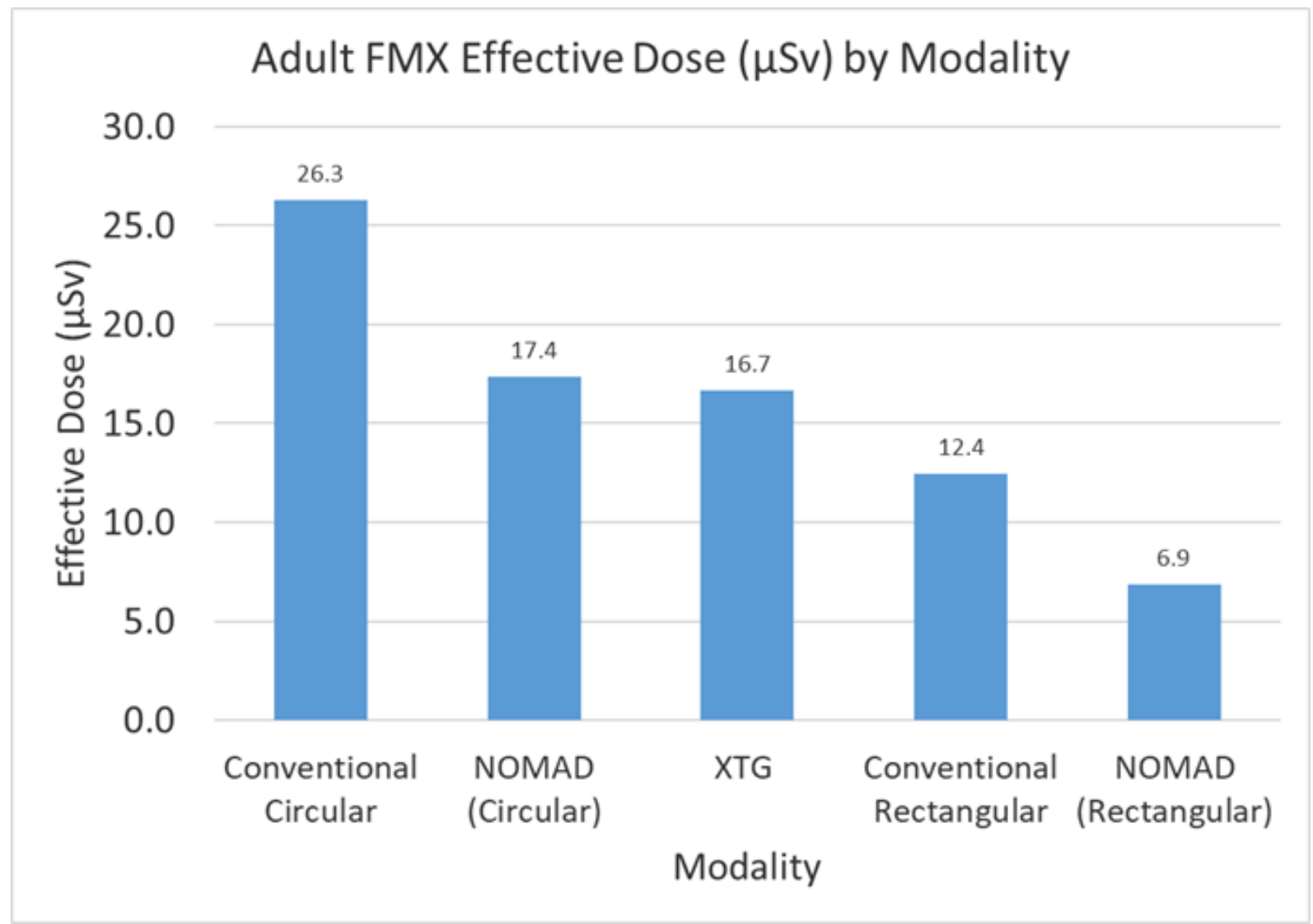

Figure 4.1: Adult Effective Dose $(\mu \mathrm{Sv})$ by Modality 


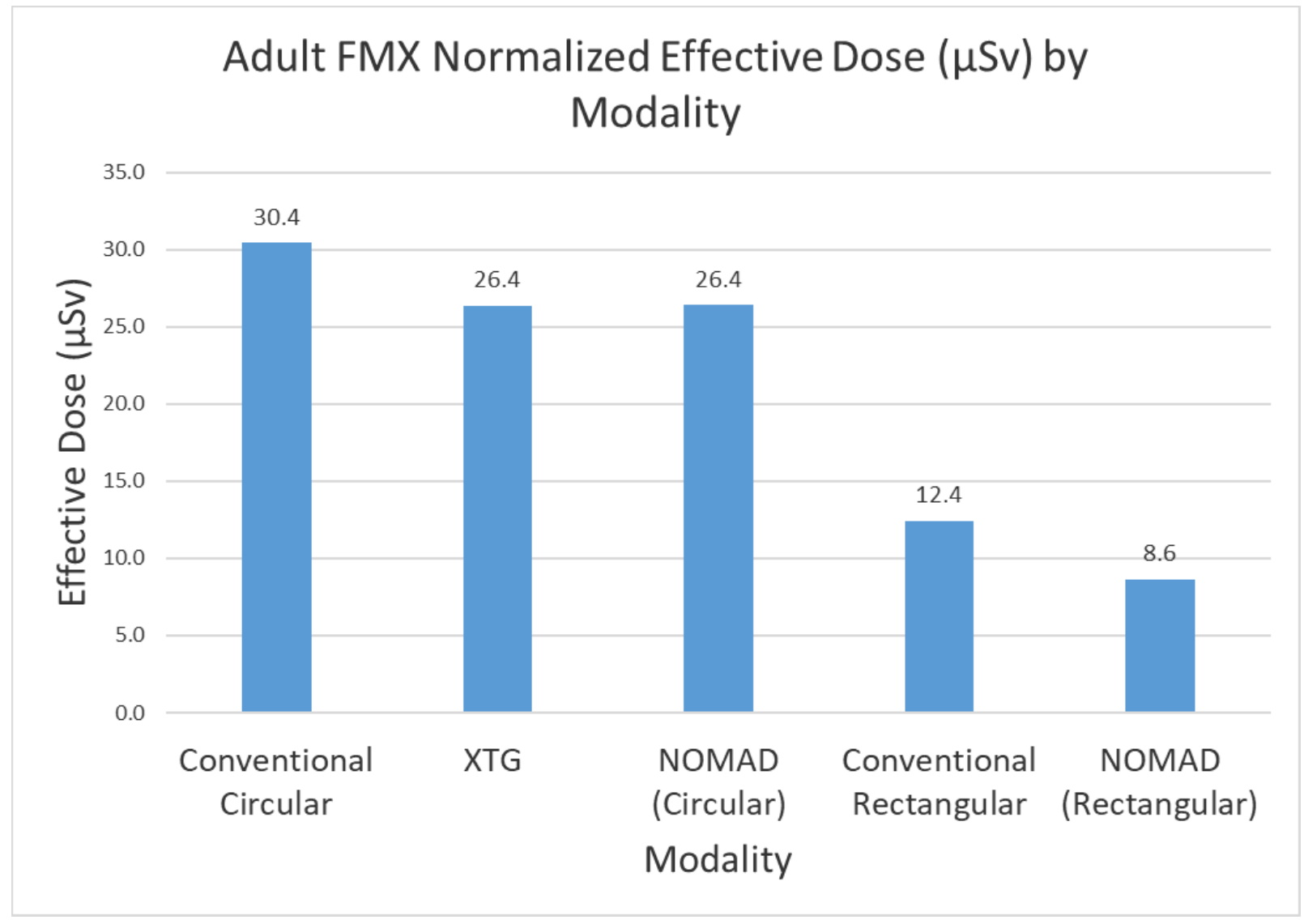

Figure 4.2: Adult Normalized Effective Dose ( $\mu \mathrm{Sv})$ by Modality 


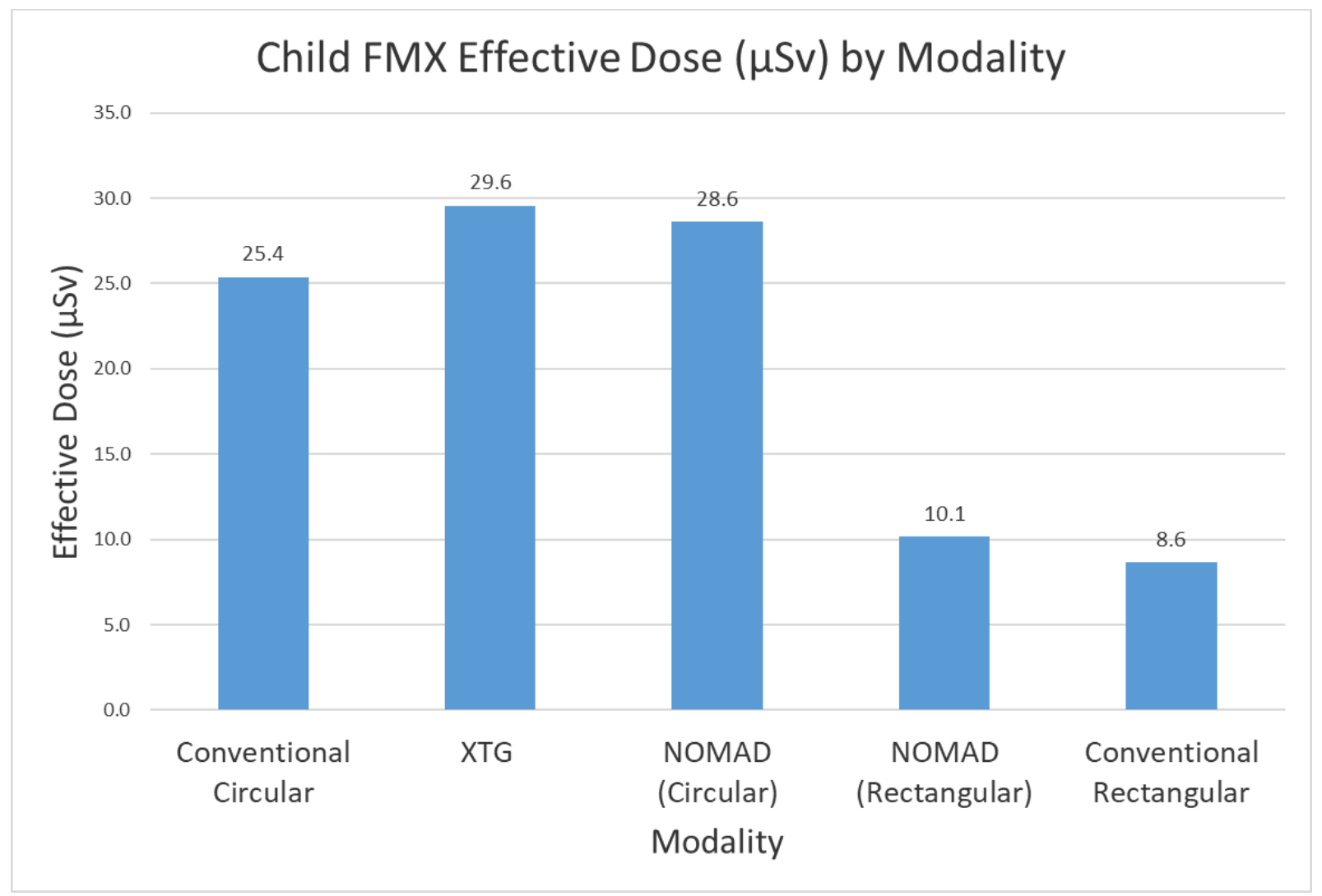

Figure 4.3: Child Effective Dose ( $\mu \mathrm{Sv})$ by Modality 


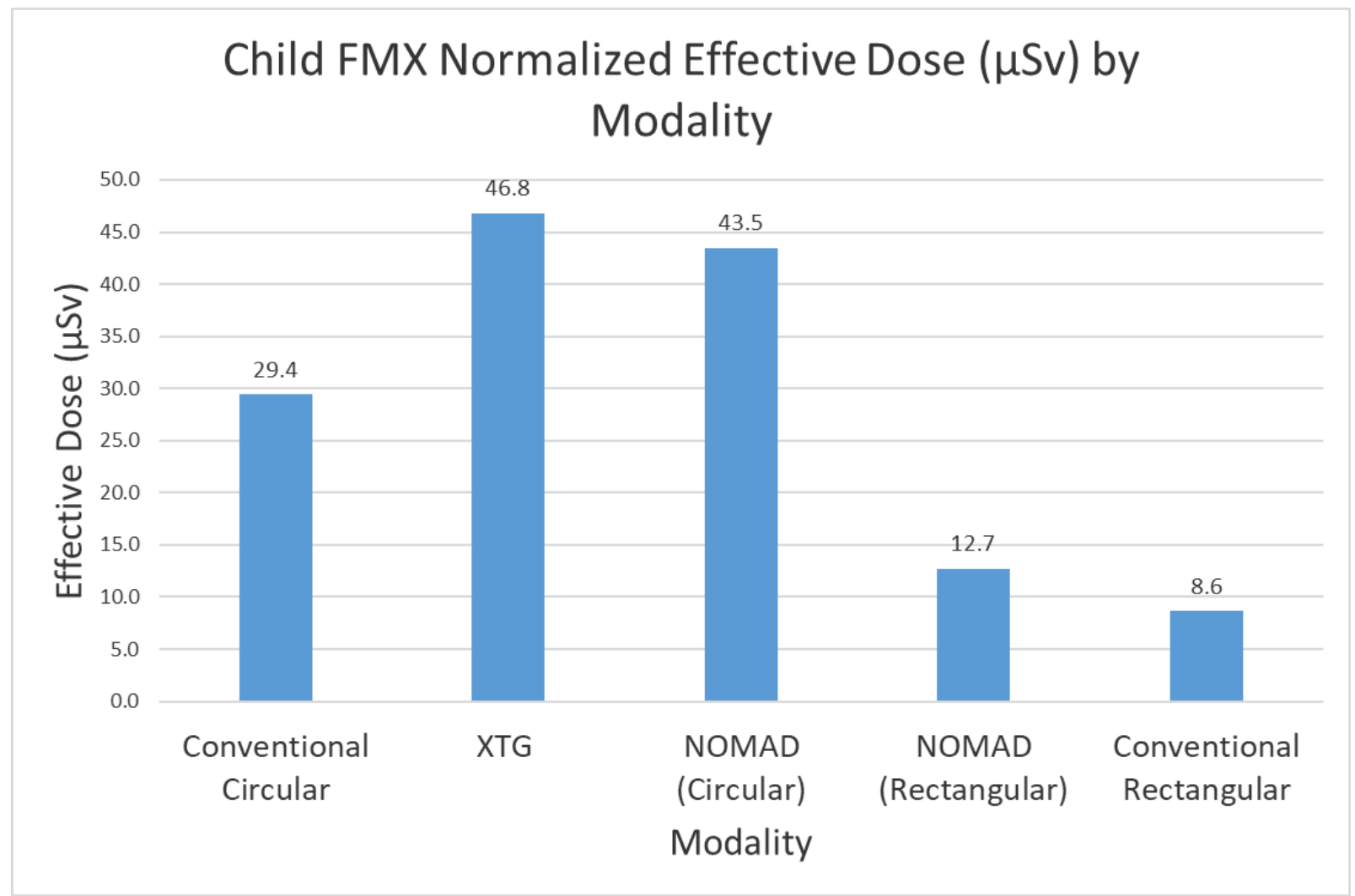

Figure 4.4: Child Normalized Effective Dose ( $\mu$ Sv) by Modality 


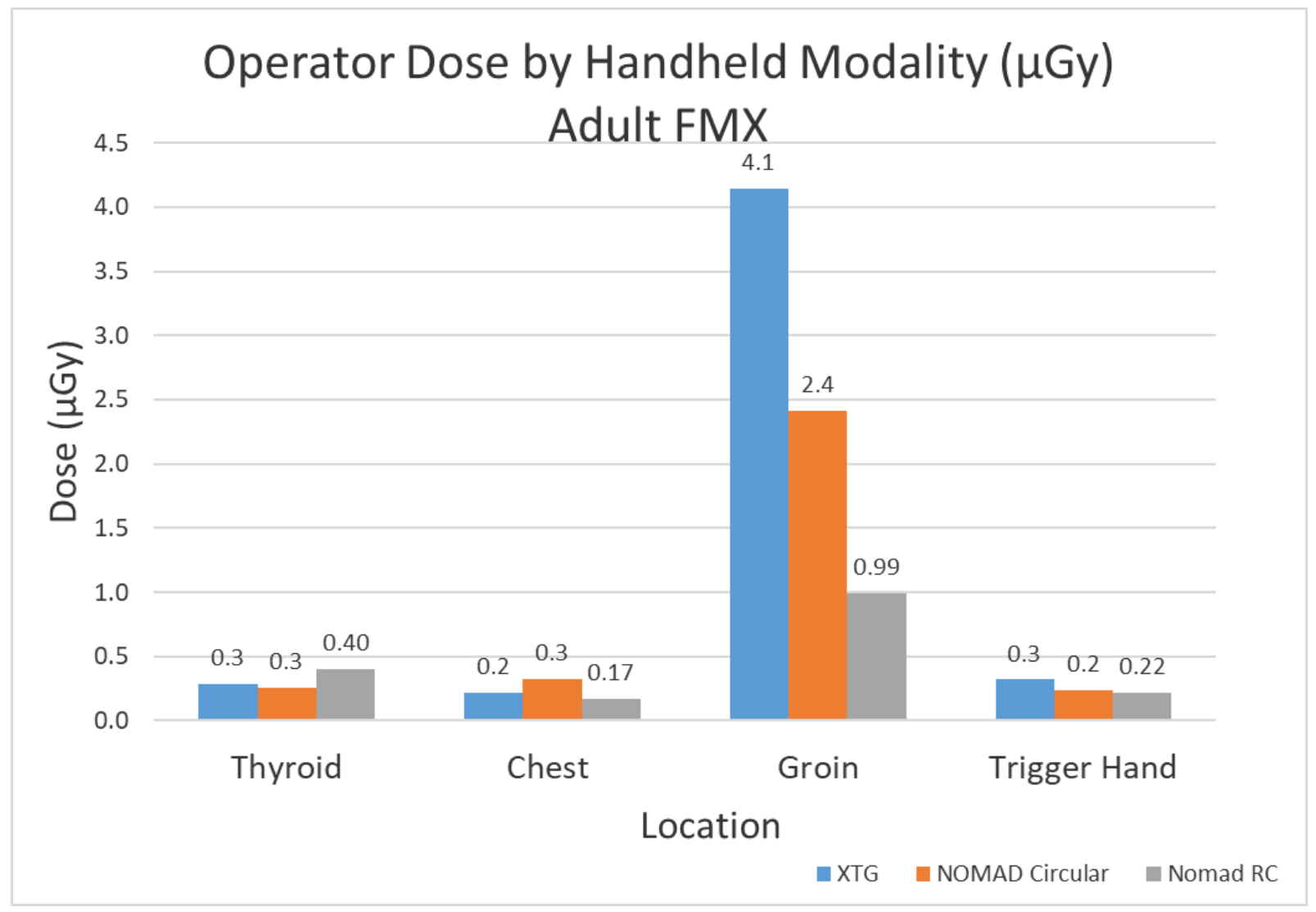

Figure 4.5: Operator Dose ( $\mu \mathrm{Gy}$ ) To the Four Areas of Interest by Handheld Modality per Adult FMX Using the Exploratory Handheld Positioning 


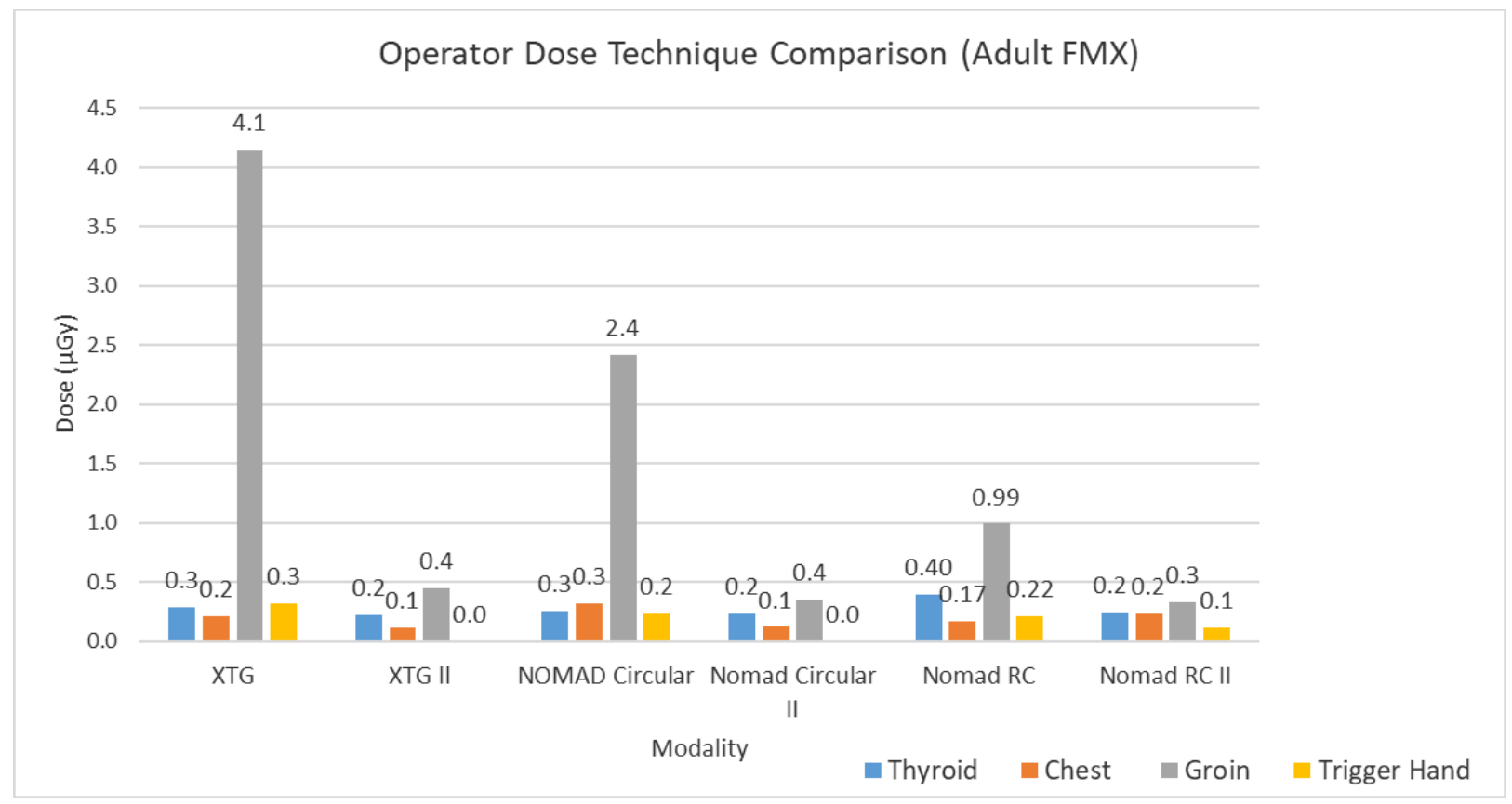

Figure 4.6: Comparing Operator Dose $(\mu \mathrm{Gy})$ To the Four Areas of Interest by Handheld Modality per Adult FMX From the Exploratory Handheld Positioning with Manufacturer Recommended Positioning. (Doses from the Manufacturer Recommended Positioning are Indicated by Roman Numeral II.) 




Figure 4.7: Operator Dose ( $\mu \mathrm{Gy}$ ) To the Four Areas of Interest by Handheld Modality per Child FMX Using the Exploratory Handheld Positioning 


\section{CHAPTER IV TABLES}

Table 4.1: Percent Reduction in Adult Effective Dose When Compared to the FOCUS ${ }^{\mathrm{TM}}$ Conventional Source with Circular Collimation

$\%$ Reduction in E from Conventional Circular

\begin{tabular}{lc}
\hline Modality & Dose \\
\hline Conventional Circular & $0 \%$ \\
NOMAD $^{\mathrm{TM}}$ Circular & $34 \%$ \\
XRay2go & $37 \%$ \\
Conventional Rectangular & $53 \%$ \\
NOMAD $^{\mathrm{TM}}$ Rectangular & $74 \%$ \\
\hline
\end{tabular}

Table 4.2: Percent Reduction in Surface Area Exposure Achieved by All Modalities

\begin{tabular}{lc}
\hline Modality & $\%$ of Conventional Circular \\
\hline Conventional Rectangular & $57 \%$ \\
NOMAD $^{\mathrm{TM}}$ Rectangular & $64 \%$ \\
XRay2go $_{\text {XRay2go with penumbra }}$ & $80 \%$ \\
Conventional Circular $^{\mathrm{TM}}$ Circular & $90 \%$ \\
NOMAD $^{\mathrm{T}}$ & $100 \%$ \\
\hline
\end{tabular}


Table 4.3: Percent Reduction in Child Effective Dose When Compared to the FOCUS ${ }^{\mathrm{TM}}$ Conventional Source with Circular Collimation

\begin{tabular}{lc}
\hline$\%$ Reduction in E from Conventional Circular \\
\hline Modality & Dose \\
\hline Conventional Circular & $0 \%$ \\
NOMAD $^{\mathrm{TM}}$ Circular & $-13 \%$ \\
XRay2go $_{\text {Conventional Rectangular }}$ & $-16 \%$ \\
NOMAD $^{\mathrm{TM}}$ Rectangular & $66 \%$ \\
\hline
\end{tabular}

Table 4.4: Frequency and Percentage of All Technique Errors by Modality

\begin{tabular}{lccc}
\hline \multicolumn{4}{c}{ Frequency and Percentage of All Techniques Errors by } \\
Modality \\
\hline \multicolumn{4}{c}{ Any Error } \\
Modality & No & Yes & Total \\
\hline Conventional Circular & 18 & 18 & 36 \\
& $50 \%$ & $50 \%$ & \\
\hline XRay2go & 25 & 11 & 36 \\
& $69.44 \%$ & $30.56 \%$ \\
\hline NOMAD $^{\mathrm{TM}}$ Rectangular & 17 & 19 & 36 \\
& $47.22 \%$ & $52.78 \%$ \\
\hline NOMAD $^{\mathrm{TM}}$ Circular & 24 & 12 \\
& $66.67 \%$ & $33.33 \%$ & 36 \\
\hline Conventional Rectangular $^{4}$ & 15 & 21 \\
& $41.67 \%$ & $58.33 \%$ & 36 \\
\hline Total & 99 & 81 & 180 \\
\hline
\end{tabular}


Table 4.5: Frequency and Percentage of All Technique Errors by Location in the Mouth Frequency and Percentage of All Techniques Errors by

\begin{tabular}{lccc}
\hline \multicolumn{4}{c}{ Location } \\
Any Error & \\
Location & No & Yes & Total \\
\hline Anterior Centrals & 38 & 7 & 45 \\
& $84.44 \%$ & $15.56 \%$ & \\
\hline Bitewing & 30 & 15 & 45 \\
& $66.67 \%$ & $33.33 \%$ & \\
\hline Mandibular Periapical & 16 & 29 & 45 \\
& $35.56 \%$ & $64.44 \%$ & \\
\hline Maxillary Periapical & 15 & 30 & 45 \\
& $33.33 \%$ & $66.67 \%$ & \\
\hline Total & 99 & 81 & 180 \\
\hline
\end{tabular}

Table 4.6: Average Number of Line Pairs Observed for Each Modality

\begin{tabular}{|c|c|c|c|c|c|}
\hline \multicolumn{6}{|c|}{ Average \# of Line Pairs Observed Among Modalities } \\
\hline Modality & XRay2go & $\begin{array}{c}\text { Conventional } \\
\text { Rectangular }\end{array}$ & $\begin{array}{c}\text { Conventional } \\
\text { Circular } \\
\end{array}$ & $\begin{array}{c}\text { NOMAD }^{\mathrm{TM}} \\
\text { Circular }\end{array}$ & $\begin{array}{l}\text { NOMAD }^{\mathrm{TM}} \\
\text { Rectangular }\end{array}$ \\
\hline Line Pair Value (SD) & $12.7(1.5)$ & $13.3(1.5)$ & $13.3(2.1)$ & $13.7(1.5)$ & $13.7(1.5)$ \\
\hline Coefficient of Variation & $12 \%$ & $11 \%$ & $16 \%$ & $11 \%$ & $11 \%$ \\
\hline
\end{tabular}




\section{CHAPTER V}

\section{DISCUSSION}

The NCRP Report No. 177 executive summary states in the last 15 years, three radiology innovations have found substantial application throughout general and specialty dentistry: digital imaging, cone-beam computed tomography and handheld intraoral imaging devices ${ }^{1}$. These developments can present a challenge to dentists who are responsible for not only learning the technology and correctly diagnosing and treating their patients, but also for developing and maintaining their own radiation safety and quality control programs.

Recommendations from sources such as the American Dental Association and the National Council on Radiation Protection and Measurements are extremely helpful for identifying best practice techniques to maximize radiation safety and optimize image quality when using handheld x-ray devices. Handheld x-ray devices that are cleared by the U.S. FDA are designed to shield the operator from source leakage radiation and backscatter radiation. A backscatter shield provides the operator with a zone of maximum protection that requires specific positioning of the device by the operator and tilting of the patient's head in some circumstances, however, non-recommended use of handheld devices where positioning is modeled after the typical conventional wall-mounted source positioning has been observed. This latter description of positioning is defined as the exploratory positioning in this study and is meant to address concerns that most operators do not adhere to strict manufacturer recommendations for a variety of reasons. Additionally, simple and inexpensive practices 
persistently recommended by radiation safety bodies, such as rectangular collimation, are still not widely used in all dental offices and even less so with handheld x-ray devices.

Although dental schools and many practicing dentists are increasingly striving to practice evidence-based dentistry, the body of literature in regard to handheld intraoral x-ray devices are relatively sparse and the previous research done varies significantly in study design. Therefore, the purpose of this study was to assess the impact of rectangular collimation with a handheld intraoral x-ray device on estimated risk to the operator and patient. The 2007 ICRP recommendations for calculating effective dose were used to estimate dose from a combination of modern imaging modalities. This study intended to present operator dose data that would represent the speculated "customary" use of handheld devices and also evaluated resultant technical performance and image quality.

The dosimetry component of the study evaluated two handheld intraoral x-ray devices and a conventional wall-mounted $\mathrm{x}$-ray source using adult and child anthropomorphic phantoms. Five modalities were evaluated (one conventional wall-mounted unit with circular and rectangular collimation, one handheld device with circular and rectangular collimation and a second handheld device using only circular collimation only). Handheld study exposures were acquired using exploratory device positionings designed to simulate the speculated use of handheld devices in every day practice versus strict adherence to the manufacturer's guidelines, where the patient must tilt their head in order for the radiographer to keep the x-ray beam parallel to the floor and perpendicular to the operator.

The technical performance and image quality component compared the performance of the five modalities including frequency of technical errors based on modality and location in the mouth and line pair analysis. Additional issues to be discussed are a comparison of patient and 
operator dose from two handheld devices and the impact of customary versus recommended positioning of handheld devices on operator dose.

\section{Patient Dosimetry}

For adult phantom dosimetry, this study found that for an 18-image full-mouth radiographic series using circular collimation, both FDA approved handheld devices resulted in effective doses that were significantly less than the conventional wall-mounted $\mathrm{x}$-ray source. Previous research has also shown a reduced effective dose using handheld x-ray devices compared to conventional wall-mounted sources ${ }^{31}$. The unadjusted effective doses achieved in this study using the handheld devices ranged from 16.7-17.4 $\mu \mathrm{Sv}$ compared to $26.3 \mu \mathrm{Sv}$ from conventional circular, which is a difference of $34-37 \%$. A non-biased quantitative normalization procedure was necessary to justify our subjective exposure optimization procedure. The average doses achieved from optimized posterior location exposure times for each modality were measured. A more ideal technique would have been to use the full FMX exposure time for each modality in order to account for variable anterior and posterior exposure times and the collective nature of effective dose. However, the technique used in this study was a good approximation.

The normalized adult effective doses using circular collimation were $26.4 \mu \mathrm{Sv}$ for the handheld devices compared to $30.4 \mu \mathrm{Sv}$ for the wall-mounted source, which is a $14 \%$ difference and were found to be significantly different $(\mathrm{p}<.0070)$. The exposure field size for all circular modalities is similar and the conventional wall-mounted source has a greater amount of filtration, so it was not expected that the wall-mounted source would achieve a higher normalized effective dose. However, when evaluating the individual tissue equivalent doses for all modalities, the conventional wall-mounted source showed generalized higher equivalent doses for all tissues when compared to both handheld devices. This difference may be explained by an increased 
source to phantom distance with the handheld devices. It is thought that as operator fatigue sets in during handheld device use, the operator tends to hold the device closer to the body. This increased distance between the source and the phantom would increase the field of exposures while concomitantly decreasing the intensity of the x-ray beam resulting in a lower dose.

Operators of a handheld device are not able to take a "step back" to observe the exact position of the device in relation to the patient or the beam alignment ring. The results of this study show that this is likely to increase the variability in device positioning. In clinical practice, a beam-aiming device should be used, and this would help control for some variations in positioning.

The results of this study can be compared to patient effective doses found from other radiographic examinations. Using the same methodology of calculating effective dose, Ludlow et. al showed the effective dose for an adult FMX with photo-stimulable phosphor (PSP) receptors or F-speed film and a conventional wall-mounted source using circular collimation to be $170.7 \mu \mathrm{Sv}^{14}$. In the current study it was demonstrated that a conventional wall-mounted source using circular collimation and direct digital sensors can decrease patient effective dose (30.4 $\mu \mathrm{Sv}$ ), and therefore risk, when compared to PSP or F-speed film. The results of this study also reinforce limiting the size of exposure field with rectangular collimation as demonstrated and recommended by several previously published studies ${ }^{1,14,32,33}$. The doses recorded in this study showed that regardless of the type of x-ray system used (handheld vs. conventional wallmounted), rectangular collimation provides the most substantial reduction in effective dose when compared to circular collimation techniques. In addition, it was found that an adult 18-image full-mouth radiographic series using direct digital CMOS sensors and the NOMAD ${ }^{\mathrm{TM}}$ handheld device with rectangular collimation resulted in the lowest effective dose and therefore risk of 
detrimental effects among all modalities tested. These findings not only support the use of handheld intra-oral x-ray devices as a safe modality for patients but show that rectangular collimation should unequivocally be applied with handheld devices to achieve optimal reductions in dose and should not be reserved for conventional wall-mounted sources.

When discussing the child dosimetry results of this study it is important to note that the exposure parameters selected at the beginning of the study were subjectively optimized for each modality using an adult phantom. For child exposures, parameters were reduced by one increment in available exposure times per x-ray device. This resulted in slight variations for time increment reductions due to differences in available unit parameters, yielding an average reduction of $10-20 \%$ compared to adult exposures. Specifically, the wall-mounted source decrease in time (sec) per click ranged from 0.008-0.017 seconds whereas the handheld devices were consistently decreased by 0.01 seconds. Ideally, the reduction in exposure time from adult to child would have an equivalent effect on all modalities. The outcome in this study resulted in a relatively more reduced mAs per child FMX for the conventional wall-mounted modalities versus the handheld modalities seen with the non-normalized effective doses. This should be considered when comparing the different wall-mounted to handheld effective dose trends of the adult versus the child procedures. In the adult procedure, the effective doses from wall-mounted modalities were higher than the effective doses from the handheld modalities. In the child procedure, where a greater reduction in mAs from the adult exposure times occurred for the wallmounted modalities, this trend was reversed. The effective doses from the wall-mounted modalities were now lower than the effective doses from the handheld modalities. In order to further investigate this trend, the normalized child effective doses were calculated and compared. 
The normalized child effective doses using circular collimation were $43.5 \mu \mathrm{Sv}$ for the $\mathrm{NOMAD}^{\mathrm{TM}}$ and $46.8 \mu \mathrm{Sv}$ for the Xray2go compared to $29.4 \mu \mathrm{Sv}$ for the wall-mounted source. This adjustment resulted in a 30\% increase for Child $\mathrm{E}$ for handheld devices. While imaging geometry for all FMX locations were designed to be consistent for all modalities, the investigator noticed a tendency to unintentionally angulate the handheld devices slightly downward during acquisitions, unlike the wall-mounted source which allowed the operator to step back to view positioning. When evaluating the individual child tissue equivalent doses from all modalities, it was noted that the thyroid tissue received a large increase in dose from the handheld modalities which may be explained due to a tendency of a downward angulation during use. If an x-ray source is angulated downward, this would contribute to a saturation of radiosensitive tissue of a child more so than with an adult due to the thyroid tissue being located physically closer to the oral cavity in children, which would therefore increase effective dose. In addition, as described previously there was a greater reduction in exposure time for the child FMX that occurred with the conventional wall-mounted source versus the handheld devices. This difference in stepdown time also correlates with the dose differences seen in the child dosimetry results.

Limited research has been completed on child dosimetry using handheld x-ray devices. A recent study by Bozic et. al concluded a child receives lower tissue equivalent doses for bitewing and anterior occlusal projections using a handheld device compared to a conventional wall-mounted unit ${ }^{34}$. More research is needed about handheld $\mathrm{x}$-ray devices using exposure parameters specifically optimized for a child FMX.

Similar to the adult dosimetry results of this study, limiting the size of the exposure field with rectangular collimation provided the greatest reduction in effective dose for a child 12image FMX when compared to circular collimation techniques. For child imaging, the 
conventional wall-mounted source with rectangular collimation achieved a lower dose compared to the NOMAD ${ }^{\mathrm{TM}}$ handheld device using rectangular collimation, however there was no statistically significant difference in dose between those modalities. The results of this study support the use of either an FDA approved handheld x-ray device or conventional wall-mounted source for intraoral imaging on children as long as rectangular collimation is used. Decreasing dose is especially important when discussing children because they are known to be more radiosensitive than adults ${ }^{33}$.

Although the effective doses in this study are meant to represent a "real world" scenario simulated by the investigator, due to limitations in phantom designs, the attenuation of $x$-rays from an intraoral imaging sensor could not be considered. The results of this study may then represent an overestimation of effective dose. Another limitation within the methodology was the optimization of exposure times based on subjective density. While this method represents how exposure parameters are selected in clinical practice, it could have created a bias in the resultant tube current-time product (mAs) values and therefore the effective doses achieved.

\section{Operator Dosimetry}

Relative to the annual occupational dose limits set by the NCRP ${ }^{35}$, the results of this study showed that all absorbed doses ( $\mu \mathrm{Gy}$ ) to the operator using the exploratory handheld device positioning technique were minimal for both adult and child FMX exams. The per FMX exposure to the areas of the thyroid, chest and trigger hand were indistinguishable from background radiation ${ }^{27}$ for all handheld modalities. The results of this study show that even when an operator does not position a handheld device according to the manufacturer's instructions, where the x-ray beam is always parallel to the floor and perpendicular to the operator, there will not be a marked increase to the operator's annual dose. 
There was however, a statistically significantly higher operator dose to the groin area for all handheld modalities for both the adult and child full mouth examinations. The groin doses from lowest value to the highest were $0.60 \mu \mathrm{Gy}\left(\mathrm{NOMAD}^{\mathrm{TM}}\right.$ with rectangular collimation for the child FMX) to $4.1 \mu \mathrm{Gy}$ (Xray2Go with circular collimation for the adult FMX). The dose per exposure for the groin was determined by averaging the FMX dose by number of exposures per FMX. This resulted in per exposure dose values for the groin region ranging from $0.05 \mu \mathrm{Gy}$ (NOMAD ${ }^{\mathrm{TM}}$ with rectangular collimation per child exposure), to $0.23 \mu \mathrm{Gy}$ (Xray2Go with circular collimation per adult exposure). These findings were used to extrapolate potential annual occupational groin tissue dose in the same manner used by the $\mathrm{NOMAD}^{\mathrm{TM}}$ User Manual ${ }^{36}$ and by Danforth et. $\mathrm{al}^{24}$ estimating 7200 radiographic exposure/year. This resulted in annual groin tissue doses ranging from $0.36 \mathrm{mGy}\left(\mathrm{NOMAD}^{\mathrm{TM}}\right.$ with rectangular collimation for child exposures) to $1.64 \mathrm{mGy}$ (Xray2Go with circular collimation for adult exposures). The highest value in this annual dose range equates to the approximate surface dose from one direct NOMAD exposure using the manufacturer's recommended settings for an adult bitewing radiograph with a digital sensor. From the tissue doses in this study, it would not be expected that an operator of handheld devices positioned at various angulation during the radiographic exam would receive an annual whole-body dose that exceeds the recommended threshold for monitoring of $1 \mathrm{mSv}$.

Danforth and colleagues evaluated operator exposure from the NOMAD ${ }^{\mathrm{TM}}$ using various typical and atypical operator positions to make a total of 915 exposures on various subjects including a training manikin, dry skulls, endodontic tooth models and forensic specimens. They also found the highest operator dose was to the reproductive area and estimated an annual reproductive area equivalent dose of $0.095 \mathrm{mSv}$ which is $0.19 \%$ of the occupational dose limit. 
The lower dose seen in their study could be explained by the use of non-human tissue equivalent imaging subjects and varying study design and methods of calculating dose. Their results do show a similar relationship to this study where positioning of handheld devices other than the manner recommended by the manufacturer results in a higher exposure to the operator groin area. The results of the study by Zenobio $e t$. $a l$ also showed operator exposure was greatest to the gonadal region and corroborate the results of the present study ${ }^{28}$.

The results of the current study show that even when positioning handheld x-ray devices in an unrecommended manner, which is anecdotally reported as a common method in private practice and dental schools, no modality tested would have a marked impact upon an operator's allowable overall whole-body annual dose. However, this study showed when rectangular collimation is used with handheld devices, a statistically significant reduction in dose to the operator is seen and should be considered the standard of practice in order to achieve the principle of ALARA.

The results of the supplemental operator dosimetry procedure performed in this study, where the devices were operated according to the manufacturer's recommended positioning, support publications from those manufacturers that this technique provides maximum protection to the operator. Doses to all areas measured were reduced compared to the exploratory positioning, however the groin area still consistently received the highest dose for all modalities tested. This study's investigator noticed that there was a tendency to hold the handheld devices close to the body and experienced a slight propensity to angulate the handheld devices toward the ground during exposures, which may have resulted in the groin area falling outside the zone of protection created by the backscatter shield and could explain the even greater groin dose from unrecommended positioning. The supplemental operator dosimetry procedure in this study 
was performed in order to compare the results from our exploratory device positioning operator dosimetry results which used the same materials, methods and operator versus comparing to the results of other studies. This portion of the study however was not repeated to test for reproducibility and as a result many possess limited reliability. A more robust comparison study could be completed in the future.

\section{Technical Performance}

When evaluating the total number of technical errors by modality, the highest number of errors resulted from exposures made with rectangular collimated modalities. However, the difference among all modalities in terms of prevalence of error was not statistically significant and device and type of collimation are therefore not a limiting factor for technical performance in this study. Both rectangular techniques resulted in an increased number of collimator centering issues; however, all cone-cuts observed in this study were cosmetic or "minor" errors that would not warrant additional patient exposure from retakes due to unimaged anatomy. Three major errors were recorded that would indicate the need for remaking the radiograph. All three of these errors were the result of incorrect vertical angulation that did not capture root apices.

The results do favor the performance of the handheld x-ray device with rectangular collimation versus the conventional wall-mounted source with rectangular collimation. This may reflect accidental tube head drift that can occur with wall-mounted sources when the operator leaves the room to activate the exposure. A previous study by Hoogeveen et. al showed that individual operators may perform better using either a handheld device or the conventional wall-mounted unit, however aiming precision appeared similar for both modalities $^{30}$. In the present study one operator made all exposures. While eliminating the 
variable of multiple radiographers, the results may reflect the individual performance trends of the single operator. It is important to note that this study's sole operator was trained on both devices according to the manufacturer's recommendations and had the same amount of experience with each device. In addition, a beam positioning device (XCP-ORA) was used in this study and therefore horizontal and vertical angulation errors evaluated may be more of an indicator of receptor placement and not a true indicator of modality performance.

There were no instances of blur or image distortion due to operator/device motion observed for any modality in this study. Brooks et. al also showed motion to be a non-factor in image quality when using the NOMAD ${ }^{\mathrm{TM}} 21$. Although maxillary and mandibular periapical images were twice as likely to have a technical error, the majority of these errors were vertical angulation in the absence of a cone cut, which is not a primary indicator of modality performance and instead that of receptor positioning. With the use of a beam alignment device in this study, the cone cuts observed were found to be the result of the restricted beam field of the rectangular collimator.

\section{Image Quality}

There was a very close agreement for observed resolution for all modalities investigated, with average values ranging by one line-pair per millimeter (12.7-13.7). For the conventional wall-mounted source and the $\mathrm{NOMAD}^{\mathrm{TM}}$, no difference was seen within devices between circular or rectangular collimation. It was hypothesized that rectangular collimated techniques may demonstrate a greater amount of subjective detail due to decreased scatter radiation; however, the line pair analysis in the study used a non-human tissue equivalent setup and therefore the effect of scatter may not be evident. An indirect relationship was seen where the smaller the focal spot size $(\mathrm{mm})$ for the $\mathrm{x}$-ray source, the higher the observed 
resolution. The NOMAD ${ }^{\mathrm{TM}}$ handheld device has the smallest focal spot size of $0.4 \mathrm{~mm}$ and demonstrated the highest observed resolution of $13.7 \mathrm{LP} / \mathrm{mm}$. The Xray2Go handheld device has the largest focal spot size of $0.8 \mathrm{~mm}$ and demonstrated the lowest observed resolution of 12.7 LP/mm. The conventional wall-mounted source has a focal spot size of $0.7 \mathrm{~mm}$ and an observed resolution of $13.3 \mathrm{LP} / \mathrm{mm}$. Previous research has shown similar diagnostic quality using handheld devices compared to conventional wall-mounted sources ${ }^{21,25}$.

The procedure used to obtain the line pair images in this study was specifically designed to reduce possible motion from the handheld modalities. However, the results may change if the handheld devices were operated in a manner which simulates clinical practice. Motion of the actual handheld device would increase the effective focal spot size and therefore increase the geometric unsharpness of the image. Therefore, controlled results of this study may not be generalizable to actual clinical conditions. The dosimetry results of this study support safe clinical research to evaluate the technical performance and image quality of handheld devices in the future.

In conclusion, the NOMAD ${ }^{\mathrm{TM}}$ and Xray2go handheld devices with circular collimation performed similarly in regard to dose for both adult and child patients and operators. Additionally, there was not a significant difference in number of technique errors between the two modalities. A greater number of line pairs $/ \mathrm{mm}$ were observed for the NOMAD ${ }^{\mathrm{TM}}$ than the Xray2Go, which may be attributable to its smaller focal spot size.

All handheld modalities evaluated revealed the highest operator dose to the area of the groin, especially when the device is positioned other than the manner recommended by the manufacturers. However, assuming full time use, the maximum estimated annual tissue doses 
in this study do not have a marked impact upon an operator's allowable overall whole-body limit of $50 \mathrm{mSv}$. Annual dose limits are set well below the known thresholds for tissue reactions and at the level where patient, societal and economic benefits outweigh the risk of stochastic effects. Therefore, U.S. FDA approved handheld intra-oral x-ray devices should be considered safe for use. This study has shown however, that the use of rectangular collimation with handheld devices significantly reduces dose to both patients and operators. Handheld devices and conventional wall-mounted $\mathrm{x}$-ray sources should not be directly compared to each other as they have fundamental differences. However, rectangular collimation is a simple and easy modification that should be the standard of care no matter what type of $\mathrm{x}$-ray source is used. In order to achieve the smallest dose to both patients and operators from handheld x-ray devices, rectangular collimation should be used while maintaining the beam parallel to the floor and perpendicular to the operator during exposures. 


\section{APPENDIX A: ATOMMAX PHANTOM LEVELS FOR DOSIMETER LOCATIONS (ADULT AND CHILD)}

CIRS ATOM Max 711 - HN Adult Phantom Levels for Dosimeter Locations

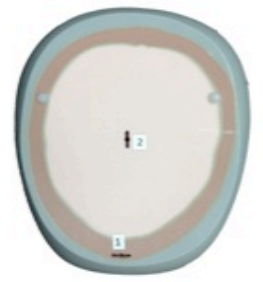

Level 2

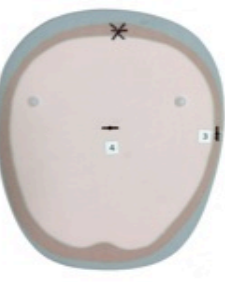

Level 3

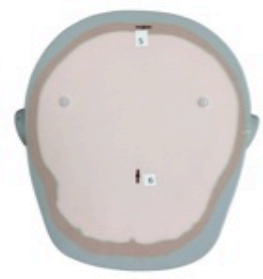

Level 4

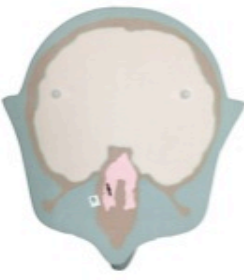

Level 5

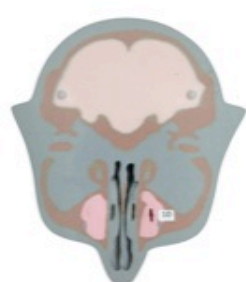

Level 6

CIRS adult phantom



Level 7

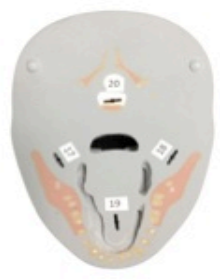

Level 8

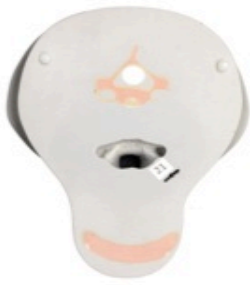

Level 9

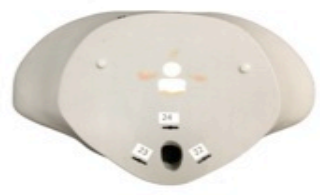

Level 10

CIRS ATOM Max 706 - HN Child Phantom Levels for Dosimeter Locations

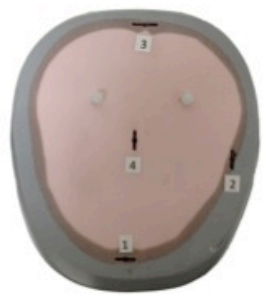

Level 2



Level 6

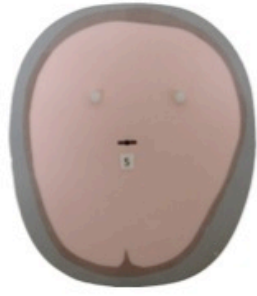

Level 3



Level 4

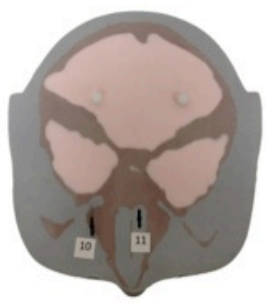

Level 5

CIRS 10 year-old child phantom



Level 7



Level 8

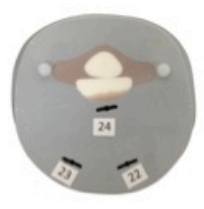

Level 9 


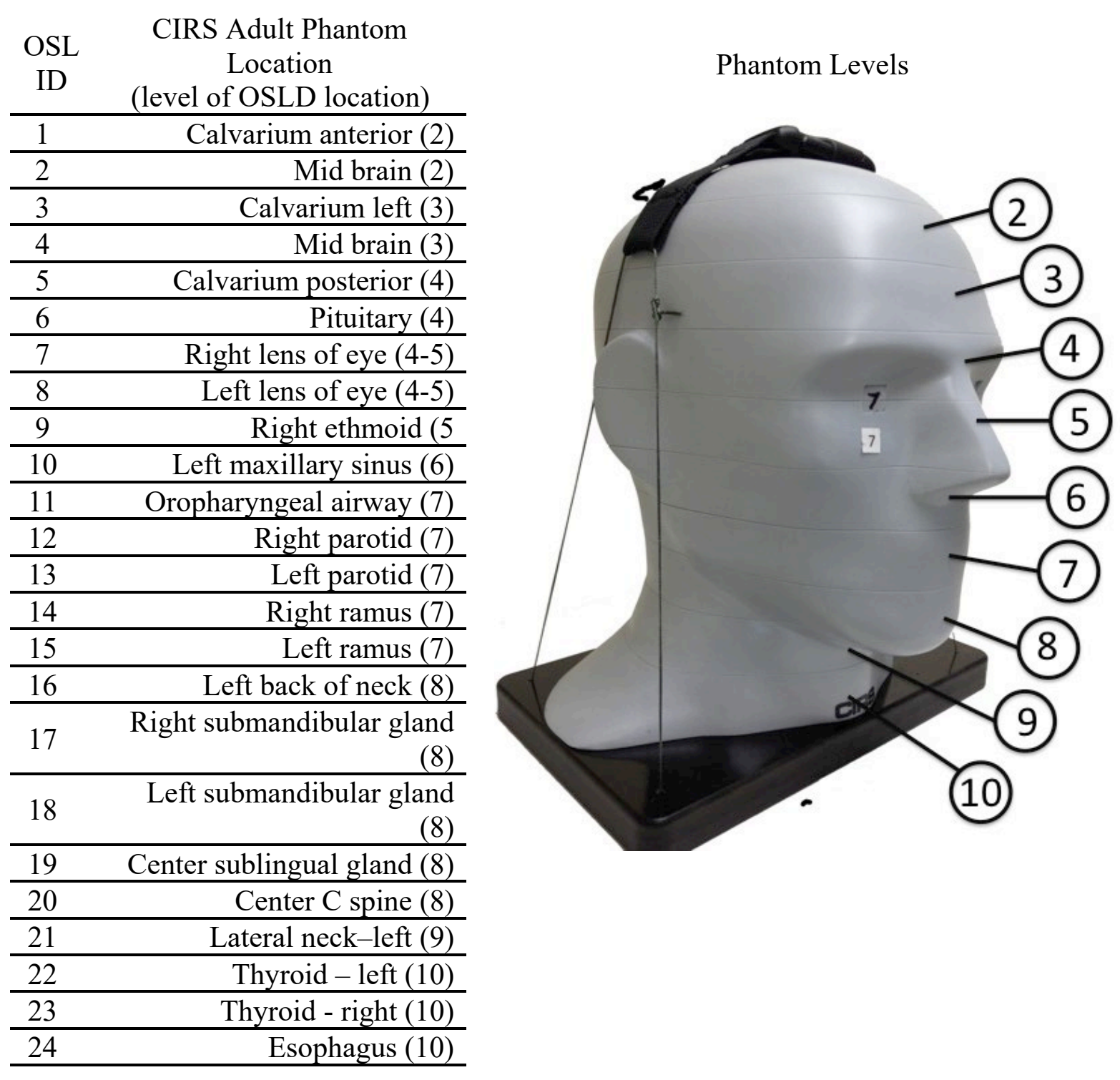




\section{APPENDIX B (CONTINUED): CIRS PHANTOM OSL \\ DOSIMETER LOCATIONS (CHILD)}

\begin{tabular}{cl}
$\begin{array}{c}\text { OSL } \\
\text { ID }\end{array}$ & $\begin{array}{l}\text { Child Phantom Location } \\
\text { (level of OSLD location) }\end{array}$ \\
\hline 1 & Calvarium anterior (2) \\
\hline 2 & Calvarium left (2) \\
\hline 3 & Calvarium posterior (2) \\
\hline 4 & Mid brain (2) \\
\hline 5 & Mid brain (3) \\
\hline 6 & Pituitary (4) \\
\hline 7 & Right orbit (4) \\
\hline 8 & Right lens of eye (4-5) \\
\hline 9 & Left lens of eye (4-5) \\
\hline 10 & Right maxillary sinus (5) \\
\hline 11 & Left nasal airway (5) \\
\hline 12 & Right parotid (6) \\
\hline 13 & Left parotid (6) \\
\hline 14 & Left back of neck (6) \\
\hline 15 & Right ramus (7) \\
\hline 16 & Left ramus (7) \\
\hline 17 & Right submandibular gland \\
& $(7)$ \\
\hline 18 & Left submandibular gland \\
\hline 19 & (7) \\
\hline 20 & Center sublingual gland (7) \\
\hline 21 & Thyroid spinerior-left (8) \\
\hline 22 & Thyroid - left (9) \\
\hline 23 & Thyroid - right (9) \\
\hline 24 & Esophagus (9) \\
\hline &
\end{tabular}

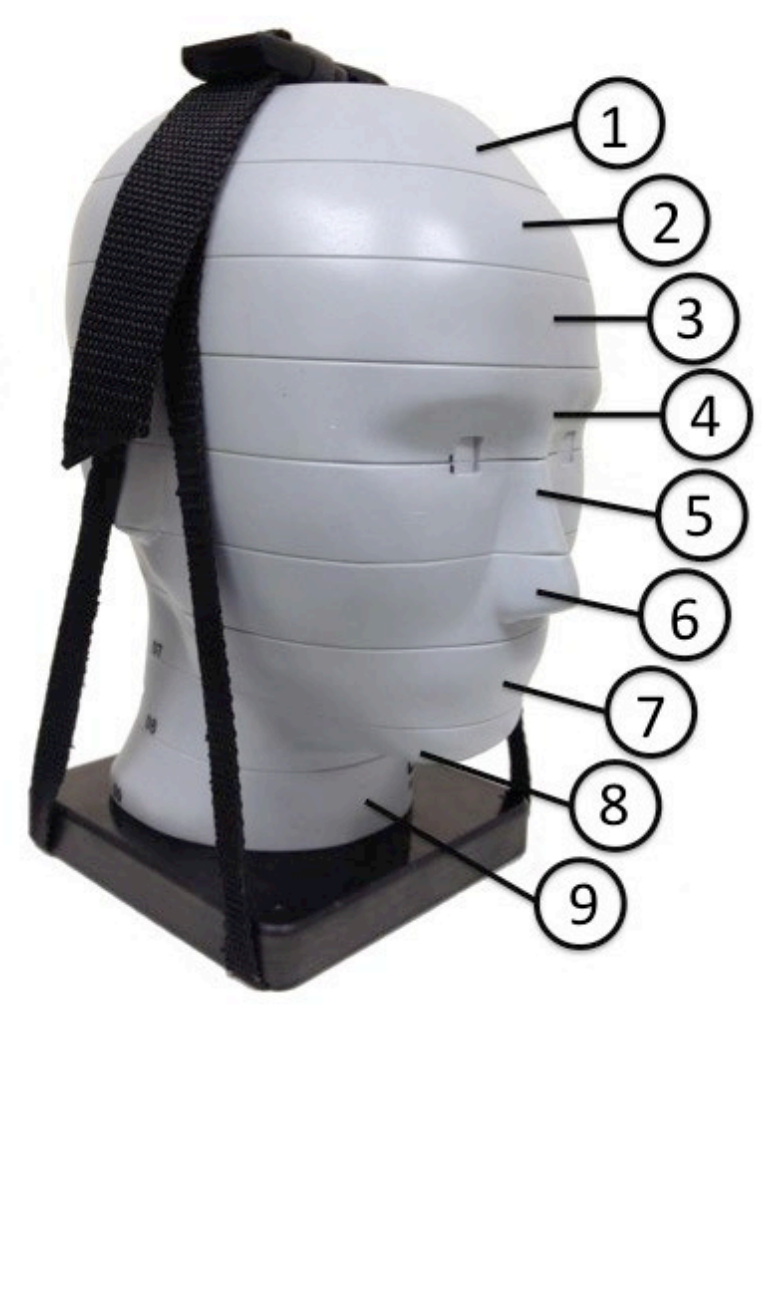


APPENDIX C: ESTIMATED PERCENT OF TISSUE IRRADIATED AND OSL LOCATIONS FOR ADULT PHANTOM

Estimated $\%$ of Tissues Irradiated and OSL Locations for Adult Phantom

Fraction

Irradiated

\begin{tabular}{lcc} 
& $(\%)$ & OSL ID \\
\hline Bone Marrow & 12.2 & \\
mandible & 0.8 & 14,15 \\
calvaria & 7.7 & $1,3,5$ \\
cervical spine & 3.8 & 20 \\
Thyroid & 100 & 22,24 \\
Esophagus & 10 & 24 \\
Skin & 5 & $7,8,16$ \\
Bone surface* & 16.5 & \\
mandible & 1.3 & 14,15 \\
calvaria & 11.8 & $1,3,5$ \\
cervical spine & 3.4 & 20 \\
Salivary Glands & 100 & \\
parotid & 100 & 12,13 \\
submandibular & 100 & 17,18 \\
sublingual & 100 & 19 \\
Brain & 100 & $2,4,6$ \\
Remainder & & \\
lymphatic nodes & 5 & $11-13,17-19,21-24$ \\
muscle & 5 & $11-13,17-19,21-24$ \\
extrathoracic airway & 100 & $9-13,17-19,21-24$ \\
oral mucosa & 100 & $11-13,17-19$ \\
\hline
\end{tabular}


APPENDIX C (CONTINUED): ESTIMATED PERCENT OF TISSUE IRRADIATED AND OSL LOCATIONS FOR CHILD PHANTOM

\begin{tabular}{|c|c|c|}
\hline \multicolumn{3}{|c|}{$\begin{array}{c}\text { Estimated \% of Tissues Irradiated and OSL Locations for } \\
\text { Child Phantom }\end{array}$} \\
\hline \multicolumn{3}{|c|}{$\begin{array}{l}\text { Fraction } \\
\text { Irradiated }\end{array}$} \\
\hline Bone Marrow & 15.4 & \\
\hline mandible & 1.1 & 15,16 \\
\hline calvaria & 11.6 & $1,2,3$ \\
\hline cervical spine & 2.7 & 20 \\
\hline Thyroid & 100 & $21,22,23$ \\
\hline Esophagus & 10 & 24 \\
\hline Skin & 5 & $8,9,14$ \\
\hline Bone surface* & 16.5 & \\
\hline mandible & 1.3 & 15,16 \\
\hline calvaria & 11.8 & $1,2,3$ \\
\hline cervical spine & 3.4 & 20 \\
\hline Salivary Glands & 100 & \\
\hline parotid & 100 & 12,13 \\
\hline submandibular & 100 & 17,18 \\
\hline sublingual & 100 & 19 \\
\hline Brain & 100 & $4,5,6$ \\
\hline \multicolumn{3}{|l|}{ Remainder } \\
\hline lymphatic nodes & 5 & $12-13,17-19,21-24$ \\
\hline muscle & 5 & $12-13,17-19,21-24$ \\
\hline extrathoracic airway & 100 & $10-13,17-19,21,24$ \\
\hline oral mucosa & 100 & $12-13,17-19$ \\
\hline
\end{tabular}




\section{APPENDIX D: ICRP 2007 RECOMMENDED TISSUE WEIGHTING FACTORS FOR CALCULATION OF EFFECTIVE DOSE}

\begin{tabular}{lc}
\hline \multicolumn{2}{c}{$\begin{array}{c}\text { Tissue Weighting Factors for } \\
\text { Calculation of Effective Dose ICRP } \\
\text { 2007 Recommendations }\end{array}$} \\
\hline Tissue & $2007 \mathrm{~W}_{\mathrm{T}}$ \\
\hline Bone marrow & 0.12 \\
Breast & 0.12 \\
Colon & 0.12 \\
Lung & 0.12 \\
Stomach & 0.12 \\
Bladder & 0.04 \\
Esophagus & 0.04 \\
Gonads & 0.08 \\
Liver & 0.04 \\
Thyroid & 0.04 \\
Bone surface & 0.01 \\
Brain & 0.01 \\
Salivary glands & 0.01 \\
Skin & 0.01 \\
Remainder Tissues & $0.12 \dagger$ \\
\hline
\end{tabular}

$\dagger$ Adrenals, Extrathoracic region, Gall bladder, Heart, Kidneys, Lymphatic nodes, Muscle, Oral Mucosa, Pancreas, Prostate, Small Intestine, Spleen, Thymus, and Uterus/cervix

(Italicized text represents remainder tissues used for calculation of maxillofacial dose) 


\title{
APPENDIX E: CRITERIA USED TO ASSESS THE TECHNICAL QUALITY OF THE PROJECTIONS
}

\author{
Performance Criteria for Intraoral Radiology
}

\section{$\underline{\text { Periapical Examinations }}$}

A. General Considerations- All periapical views should demonstrate:

1. $\quad 1 / 4$ inch of alveolar bone visible beyond the apex of each tooth.

2. $1 / 16-1 / 8$-inch margin between the crowns of the teeth and the edge of the image.

3. Occlusal plane should be straight or slightly curved upward toward the distal.

B. Specific Views

1. Maxillary Centrals

The central/central interproximal space is centered on the film. Demonstrate the central incisors, lateral incisors, the proximal portion of canines, incisive foramen, and nasal fossa. Interproximal spaces open with emphasis between the central incisors.

2. Maxillary Molar

Demonstrate the entire first molar, second molar, and third molar or most distal tooth present. Interproximal spaces open with emphasis between the first and second molar.

3. Mandibular Molar

Demonstrate the entire first molar, second molar, and third molar or most distal tooth. Interproximal spaces open with emphasis between the first molar and the second molar.

\section{Interproximal (Bitewing) Examinations}

A. General Considerations- All interproximal (bitewing) views:

1. Occlusal plane should be straight or slightly curved upward toward the distal.

2. Equal distribution (demonstration) of maxillary and mandibular crowns, and maxillary alveolar crests.

B. Specific Views

1. $\underline{\text { Molar }}$

Demonstrate all of the first molar, second molar, and third molar crowns or the crowns of the most distal tooth present. Interproximal spaces open with emphasis between maxillary first molar and second molar. Note: because of the difference in tooth morphology (maxillary molars are rhomboid and mandibular molars are trapezoid) and arch form, it may be difficult to open maxillary and mandibular contacts simultaneously; if this is the case, favor opening the maxillary molar contacts. 


\section{REFERENCES}

1. National Council on Radiation Protection and Measurements. Radiation protection in dentistry and oral \& maxillofacial imaging: Recommendations of the National Council on Radiation Protection and Measurements. Bethesda, MD: National Council on Radiation Protection and Measurements; 2019.

2. The International Commission on Radiological Protection. The 2007 Recommendations of the Interntional Commission on Radiological Protection. annals of the icrp. 2007.

3. Gray JE, Bailey ED, Ludlow JB. Dental staff doses with handheld dental intraoral x-ray units. Health Phys. 2012;102(2):137-142. doi:10.1097/HP.0b013e318230778a

4. McGiff TJ, Danforth RA, Herschaft EE. Maintaining radiation exposures as low as reasonably achievable (ALARA) for dental personnel operating portable hand-held x-ray equipment. Health Phys. 2012;103(2 Suppl 2):S179-85.

doi:10.1097/HP.0b013e318259fa29

5. CRCPD Committee on Quality Assurance in Diagnostic X-Ray (H-7). Q.A. Collectible Handheld Dental X-ray Units. Conference of Radiation Control Programs Directors, Inc.; 2010.

6. Mahdian M, Pakchoian AJ, Dagdeviren D, et al. Using hand-held dental x-ray devices: ensuring safety for patients and operators. J Am Dent Assoc. 2014;145(11):1130-1132. doi:10.14219/jada.2014.85

7. Coy J, Vandre RH, Davidson WR. Use of the hand-held dental X-ray machine during joint operation, NATO exercise Display Determination-92. Mil Med. 1997;162(8):575-577.

8. Aribex awarded patents for NOMAD handheld X-ray system. https://www.newsmedical.net/news/2009/01/19/45120.aspx. Published January 19, 2009. Accessed March 1, 2020 .

9. Berkhout WER, Suomalainen A, Brüllmann D, Jacobs R, Horner K, Stamatakis HC. Justification and good practice in using handheld portable dental X-ray equipment: a position paper prepared by the European Academy of DentoMaxilloFacial Radiology (EADMFR). Dentomaxillofac Radiol. 2015;44(6):20140343. doi:10.1259/dmfr.20140343

10. Rottke D, Gohlke L, Schrödel R, Hassfeld S, Schulze D. Operator safety during the acquisition of intraoral images with a handheld and portable X-ray device. Dentomaxillofac Radiol. 2018;47(3):20160410. doi:10.1259/dmfr.20160410 
11. Seilern-Moy K, Vielgrader H, Gerritsmann H, Walzer C. Radiography in the field: assessing a lightweight, handheld, battery-powered dentistry unit for field diagnostic applications. J Zoo Wildl Med. 2017;48(1):31-39. doi:10.1638/2016-0034.1

12. Icrp. Icrp Publication 60: 1990 Recommendations Of The International Commission On Radiological Protection. 1st ed. Sage Publications Ltd; 1991:215.

13. Thurston J. NCRP Report No. 160: Ionizing Radiation Exposure of the Population of the United States. Phys Med Biol. 2009;55(20).

14. Ludlow J, Davies-Ludlow L, White S. Patient risk related to common dental radiographic examinations. The impact of 2007 International Commission on Radiological Protection recommendations regarding dose calculation. J Am Dent Assoc. 2008;139:1237-1243.

15. Nolan WE. Radiation Hazards to the Patient from Oral Roentgenography. The Journal of the American Dental. December 1953.

16. Richards AG, Colquitt WN. Reduction is Dental X-ray Exposures During the Past 60 Years. The Journal of the American Den. 1981;103:713-718.

17. Richards AG. Sources of X-radiation in the dental office. Dent Radiogr Photogr. 1964.

18. Zielinski JM, Garner MJ, Krewski D, et al. Decreases in occupational exposure to ionizing radiation among Canadian dental workers. $J$ Can Dent Assoc. 2005;71(1):29-33.

19. Kumazawa S, Nelson DR, Richardson ACB. Occupational Exposure to Ionizing Radiation in the United States: A Comprehensive Review for the Year 1980 and a Summary of Trends for the Years 1960-1985.; 1984.

20. Eheman CR, Tolbert PE. Estimating occupational radiation doses when individual dosimetry information is not available: a job exposure matrix. Am J Ind Med. 1999;36(3):348-359. doi:10.1002/(sici)1097-0274(199909)36:3<348::aid-ajim2>3.0.co;2-r

21. Brooks SL, McMinn WE, Benavides E. A clinical trial of the Nomad portable X-ray unit. Journal Michigan. 2009;91:54-58.

22. Goren AD, Bonvento M, Biernacki J, Colosi DC. Radiation exposure with the NOMAD portable X-ray system. Dentomaxillofac Radiol. 2008;37(2):109-112. doi: $10.1259 / \mathrm{dmfr} / 33303181$

23. Hermsen KP, Jaeger SS, Jaeger MA. Radiation safety for the NOMAD portable X-ray system in a temporary morgue setting. J Forensic Sci. 2008;53(4):917-921. doi:10.1111/j.1556-4029.2008.00766.x 
24. Danforth RA, Herschaft EE, Leonowich JA. Operator exposure to scatter radiation from a portable hand-held dental radiation emitting device (Aribex NOMAD) while making 915 intraoral dental radiographs. J Forensic Sci. 2009;54(2):415-421. doi:10.1111/j.15564029.2008.00960.x

25. Pittayapat $\mathrm{P}$, Oliveira-Santos $\mathrm{C}$, Thevissen $\mathrm{P}$, et al. Image quality assessment and medical physics evaluation of different portable dental X-ray units. Forensic Sci Int. 2010;201(13):112-117. doi:10.1016/j.forsciint.2010.04.041

26. Cho J-Y, Han W-J. The reduction methods of operator's radiation dose for portable dental X-ray machines. Restor Dent Endod. 2012;37(3):160-164. doi:10.5395/rde.2012.37.3.160

27. Makdissi J, Pawar RR, Johnson B, Chong BS. The effects of device position on the operator's radiation dose when using a handheld portable X-ray device. Dentomaxillofac Radiol. 2016;45(3):20150245. doi:10.1259/dmfr.20150245

28. Zenóbio EG, Zenóbio MA, Azevedo CD, Nogueira M do S, Almeida CD, Manzi FR. Assessment of image quality and exposure parameters of an intraoral portable X-rays device. Dentomaxillofac Radiol. 2019;48(3):20180329. doi:10.1259/dmfr.20180329

29. Smith R, Tremblay R, Wardlaw GM. Evaluation of stray radiation to the operator for five hand-held dental X-ray devices. Dentomaxillofac Radiol. 2019;48(5):20180301. doi:10.1259/dmfr.20180301

30. Hoogeveen RC, Meertens BR, Berkhout WER. Precision of aiming with a portable X-ray device (Nomad Pro 2) compared to a wall-mounted device in intraoral radiography. Dentomaxillofac Radiol. 2019;48(5):20180221. doi:10.1259/dmfr.20180221

31. Phillips BJ. A Comparison of Intraoral Image Quality, Error Rates, Operator and Patient Dosimetry Between a Hand-Held Device and Wall-mounted X-ray Sources. 2014.

32. American Dental Association Council on Scientific Affairs. The use of dental radiographs: Update and recommendations. J Am Dent Assoc. 2006;137:1304-1312.

33. Mallya S, Lam E. White and Pharoah's Oral Radiology: Principles and Interpretation. 8th ed.; 2019.

34. Bozic Z, Yepes J, Jones J, Sanders B, Vinson L, Johnson B. Pediatric phantom dosimetry using a hand-held portable dental radiology device. Annals of Dentistry and Oral Health. March 2020. 
35. National Council on Radiation Protection and Measurements. Management of exposure to ionizing radiation: Radiation protection guidance for the United States (2018). Bethesda, MD: National Council on Radiation Protection and Measurements; 2018.

36. NOMAD Pro 2 Handheld X-ray System for Intraoral Radiographic Imaging. 